\title{
Flora of vascular plants on Oenarodo Island
}

\section{Seung Hyun HWANG, Eun Hwa LA ${ }^{1}$, Jin Woong LEE $^{2}$ and Jin Kap AHN ${ }^{1 *}$}

\author{
Department of Biology, Daejeon University, Daejeon 34520, Korea \\ ${ }^{1}$ Department of Life Sciences, Chonbuk National University, Jeonju 54896, Korea \\ ${ }^{2}$ Natural Environmental Restoration Institute, Daejeon 34428, Korea \\ (Received 30 May 2019; Revised 14 June 2019; Accepted 21 June 2019)
}

\begin{abstract}
This study presents the flora of vascular plants on Oenarodo Island, located in Goheung-gun, Jeollanam-do, Korea. A list of vascular plants was created based on the herbarium of the National Biological Resource Center (NIBR) and the Daejeon University Biology Department herbarium (TUT) collected from field surveys. Based on specimens collected in the field during 21 separate field trips amounting to a total of 21 days conducted between March of 2015 and October of 2017, there are 587 taxa on Oenarodo Island, consisting of 122 families, 364 genera, 538 species, six subspecies, 41 varieties, and two forms. Among the collected plants, those endangered were four taxa, those endemic were 14 taxa, floristic regional indicator plants specially designated by the Ministry of the Environment amounted to 137 taxa, and those naturalized amounted to 46 taxa.
\end{abstract}

Keywords: Oenarodo Island, flora, endemic, endangered plants, naturalized plants

전라남도 고흥군 봉래면에 위치한 외나로도는 대한민 국 남단 고흥반도 자락에 위치해 있으며, 지리적으로 북 위 $34^{\circ} 24^{\prime}-34^{\circ} 28^{\prime}$, 동경 $127^{\circ} 27^{\prime}-127^{\circ} 32^{\prime}$ 사이에 위치한 식물 구계학적으로 남해안아구(Lee and Yim, 2002)에 해당된다. 외나로도는 섬 전체가 다도해해상국립공원에 속해있다. 외나로도 일원의 식물상은 Kim and Oh (1997)가 상록활엽 수림 연구를 통하여 외나로도를 포함 부속섬인 애도 및 사양도에 대한 연구를 수행하였고, Park (2007)이 나로도 의 식생에 대한 연구를 수행한 바 있다. Kim and Park (2004) 은 고흥군의 자연환경 생태조사를 통하여 나로도(내나로 도, 외나로도)의 식물분포에 관해 872 분류군을 보고하였 으며, Kim and Oh (2010)는 다도해국립공원의 귀화식물 분포 특성을 통하여 외나로도의 귀화식물 분포를 연구하 였다. 또한 Kim et. al. (2016)은 남해안 도서식물상의 지리 학적 특성에 대하여 연구하였다. 외나로도의 식물상 연구 로는 Hwang et al. (2014)에 의하여 574분류군이 보고되었 다. 그러나 외나로도의 식물상 선행연구에서는 2009년 6 월 나로우주센터가 준공된 이후로 일반인의 출입이 제한 되어 외나로도의 식물상에 대한 연구가 제대로 이루어진 바가 없었다. 따라서, 본 연구를 통하여 외나로도 일원의 생태계 현황을 밝히고 생태적 가치를 발굴하여 종다양성 보전을 위한 기초자료를 제공하고자 한다. 본 연구는 봉 래산 $(410 \mathrm{~m})$, 장포산 $(360 \mathrm{~m})$, 마치산 $(368 \mathrm{~m})$ 과 해안가, 저
지대를 비롯하여 일반인의 접근이 불가한 나로우주센터 및 우주센터와 인접한 해안가의 식물상을 조사하여 보고 한다.

\section{재료 및 방법}

현지조사는 2015년 3월부터 2017년 10월까지 3년 동안 총 21회에 걸쳐 이루어졌다(Table 1). 조사범위는 일반인 의 접근이 금지되어 있는 나로우주센터와 주변지역을 포함하여 외나로도의 접근 가능지역에 대하여 조사를 실시하였다(Fig. 1). 조사지역에 생육하는 모든 식물을 채집하여 압착·건조 후 표본으로 제작하여 국립생물자 원관 석엽표본관(NIBR)과 대전대학교 표본실(TUT)에 보관하였으며, 확증표본 및 화상자료를 근거로 식물상 목록을 작성하였다. 식물의 동정 및 분류는 W. T. Lee (1996), T. B. Lee (1980, 2003), Y. N. Lee (1998, 2006), Park (2009) 등의 도감을 이용하였으며, 식물의 분류체계 는 한반도 관속식물 속식물지(Park, 2007)를 따랐고, 과 내에서 알파벳순으로 속명과 종소명을 정리하였다. 학 명과 국명은 국가생물종목록집-관속식물-(National Institute of Biological Resources, 2019)을 참고하였다. 또 한, National Institute of Ecology (2018)의 "Floristic Taget Species (FT species) in Korea" 자료를 바탕으로 식물구계

\footnotetext{
*Author for correspondence: jinkabi@hanmail.net
} 


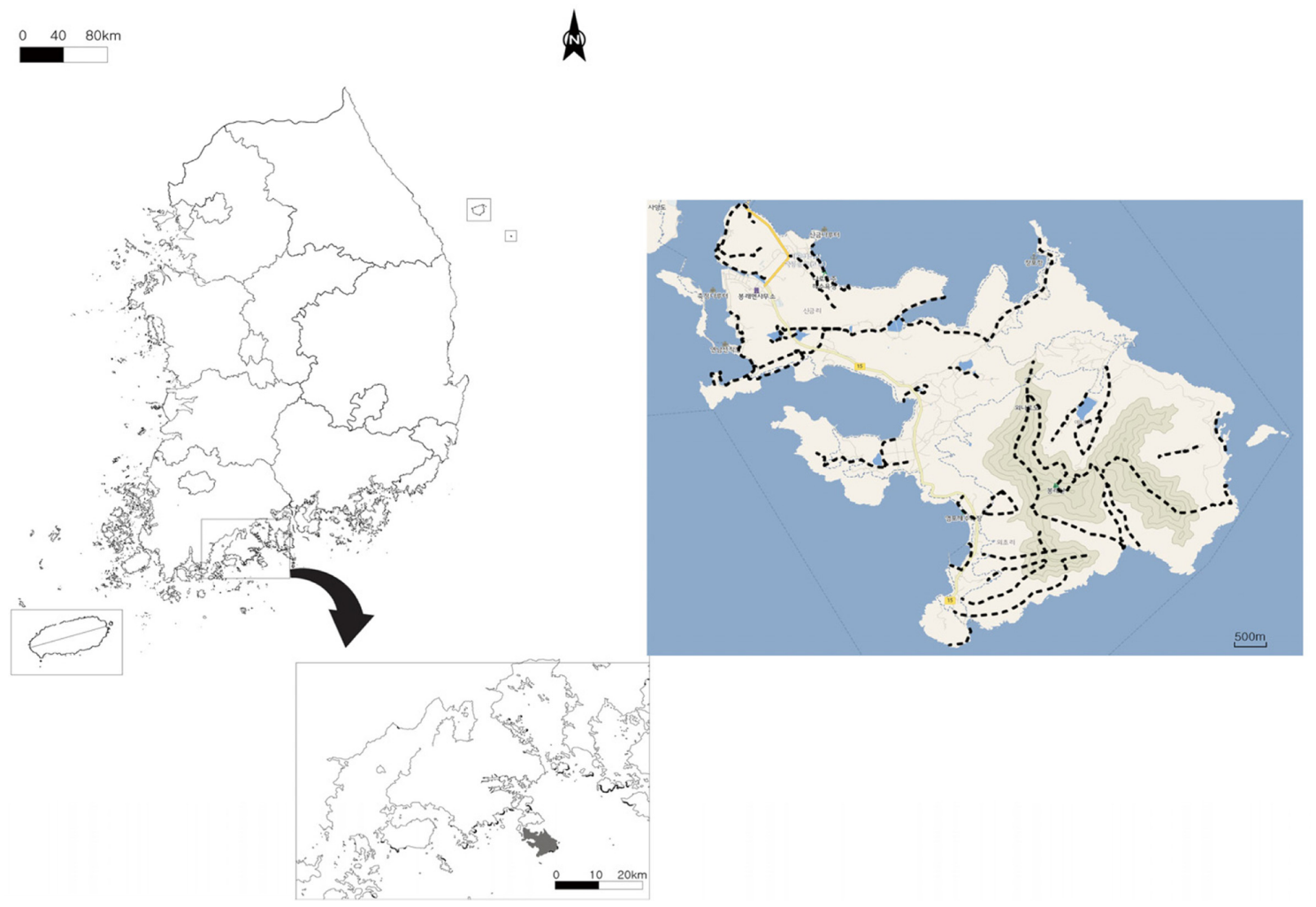

Fig. 1. Map of investigation area and survey routes.

Table 1. The dates and routes of investigations.

\begin{tabular}{crl}
\hline \hline No. & \multicolumn{1}{c}{ Dates } & \\
\hline 1 & 19 Mar 2015 & Yenae-Reservoir $\rightarrow$ Upper valley, Around Naro Space Center \\
2 & 4 Apr 2015 & Hachon willage $\rightarrow$ Jangposan Mt. $\rightarrow$ Yeongpo village \\
3 & 15 Apr 2015 & Planned Space Land \\
4 & 23 May 2015 & Bonglaesan Mt. Parking Lot $\rightarrow$ Bonglaesan Mt. $\rightarrow$ Jangposan Mt. $\rightarrow$ Machisan Mt. $\rightarrow$ Woodland forest $\rightarrow$ \\
& & Bonglaesan Mt. Parking Lot \\
5 & 17 Jun 2015 & Yenae-ri $\rightarrow$ Sileum hill, Yenae-ri beach \\
6 & 18 Jun 2015 & Around Naro Space Center \\
7 & 1 Aug 2015 & Hachon village $\rightarrow$ Jangposan Mt. \\
8 & 9 Sep 2015 & Machisan Mt. valley \\
9 & 10 Sep 2015 & Machisan Mt. $\rightarrow$ Naro Space Center \\
10 & 19 Mar 2016 & Bonglaesan Mt. $\rightarrow$ Sileum hill $\rightarrow$ Yenae-ri \\
11 & 14 May 2016 & Sileum hill $\rightarrow$ Jangposan Mt. $\rightarrow$ Jangposan Mt. valley \\
12 & 23 Jul 2016 & Yenae Reservoir $\rightarrow$ Upper valley $\rightarrow$ Bonglaesan Mt. $\rightarrow$ Sileum hill \\
13 & 7 Oct 2016 & Yenae-ri $\rightarrow$ Sileum hill \\
14 & 8 Mar 2017 & Yenae Reservoir $\rightarrow$ Upper valley $\rightarrow$ Sileum hill \\
15 & 25 Mar 2017 & Sileum hill $\rightarrow$ Jangposan Mt. valley $\rightarrow$ Machisan Mt. valley \\
16 & 18 Apr 2017 & Around Singeum-ri \\
17 & 19 Apr 2017 & Oecho-ri valley \\
18 & 20 Apr 2017 & Eomnam village beach \\
19 & 22 Jun 2017 & Naro Space Center $\rightarrow$ Sileum hill $\rightarrow$ Mt. Jangposan valley \\
20 & 28 Aug 2017 & Oecho-ri $\rightarrow$ Yenae-ri $\rightarrow$ Around Singeum-ri \\
21 & 21 Oct 2017 & Oecho-ri $\rightarrow$ Yenae-ri $\rightarrow$ Singeum-ri marsh \\
\hline
\end{tabular}



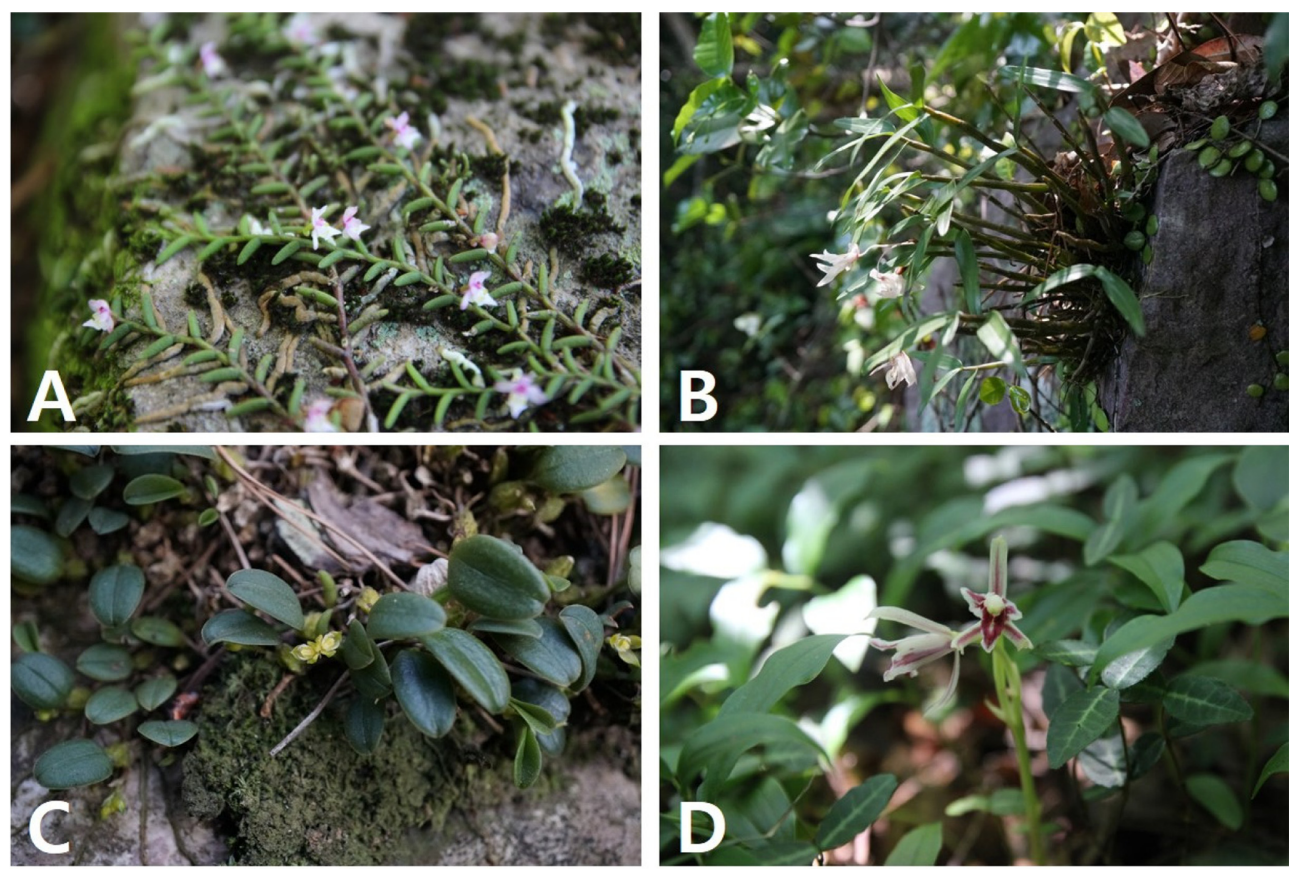

Fig. 2. The endangered plants in the Oenarodo Island. A. Cleisostoma scolopendrifolium (Makino) Garay. B. Dendrobium moiliforme Sw. C. Bulbophyllum inconspicuum Maxim. D. Cymbidium macrorrhizon Lindl.

Table 2. The number of vascular plants distributed in the Oenarodo Island.

\begin{tabular}{lccccccc}
\hline \multicolumn{1}{c}{ Taxa } & Family & Genus & Species & Subspecies & Variety & Forma & Total \\
\hline Pteridophyta & 14 & 23 & 42 & - & 1 & - & 43 \\
Gymnospermae & 2 & 4 & 4 & - & - & - & 4 \\
Angiospermae & 106 & 337 & 492 & 6 & 40 & 2 & 540 \\
Dicotyledons & 92 & 253 & 352 & 4 & 28 & 1 & 385 \\
Monocotyledons & 14 & 84 & 140 & 2 & 12 & 1 & 155 \\
Total & 122 & 364 & 538 & 6 & 41 & 2 & 587 \\
\hline
\end{tabular}

Table 3. The endangered plants to Korea in Oenarodo Island by Ministry of Enviroment.

\begin{tabular}{|c|c|c|}
\hline Family & Scientific names/Korean name & Grade \\
\hline \multirow[t]{4}{*}{ Orchidaceae난초과 } & Bulbophyllum inconspicuum Maxim. 혹난초 & II \\
\hline & Cleisostoma scolopendrifolium (Makino) Garay 지 네 발란 & II \\
\hline & Cymbidium macrorrhizon Lindl. 대흥란 & II \\
\hline & Dendrobium moiliforme $\mathrm{Sw}$. 석곡 & II \\
\hline
\end{tabular}

학적 특정식물에 대하여 논의하였으며, 한반도 고유종 은 National Institute of Biological Resources (2014)에서 발 간한 "한반도 고유종(Endemic Species of Korea)"을 따랐 고, 멸종위기야생식물은 National Institute of Biological Resources (2012)의 자료에 준하였다. 희귀식물은 Korea National Arboretum (2008)에서 발간한 “한국의 희귀식물 목록(IUCN 평가기준)"을 토대로 작성하였으며 귀화식 물과 생태계교란야생식물은 Lee et al. (2011)과 Park (2009)의 자료를 참고하였다.

\section{결 과}

\section{관속식물상}

확증표본을 근거로 한 외나로도 일대의 관속식물은 122 과 364속 538종 6아종 41변종 2품종의 총 587분류군으로 확인되었다(Table 2). 이 중 양치식물은 14 과 13속 42종 1 변 종으로 총 43 분류군, 나자식물은 2과 2속 4종으로 총 4 분 류군, 피자식물 중 쌍자엽식물은 92과 352속 352종 4아종 28 변종 1품종으로 총 385 분류군, 단자엽식물은 14 과 78 속 
140 종 2아종 12변종 1품종으로 총 155분류군으로 구성되 었다(Table 2). 따라서 최근에 유입된 귀화식물을 비롯하 여 한반도에 약 4,881분류군(A Synonymic List of Vascular Plants in Korea; Korea National Arboretum and The Korean Society of Plant Taxonomists, 2007)의 식물이 자라는 점을 감안했을 때, 외나로도 일대에 분포하는 식물종은 한반도 전체 식물 중 약 $12 \%$ 정도가 외나로도 일대에 분포하는 것으로 나타났다.

\section{멸종위기야생생물}

외나로도 일원에서 환경부 지정 멸종위기야생생물은 II 급인 혹난초, 지네발란, 대흥란, 석곡 4 분류군이 확인되었 다(Fig. 2, Table 3).

\section{한반도고유종}

외나로도 일대의 한반도고유종 식물은 변산바람꽃, 새 끼노루귀, 해변싸리, 거제물봉선 등 14 분류군의 생육이 확인되었으며(Table 4), 외나로도 지역에서 조사된 관속식
물 587 분류군의 $2.38 \%$ 에 해당한다. 변산바람꽃, 새끼노루 귀 등은 대부분 봉래산 편백나무 숲 계곡부에 분포하고 있었으며, 거제물봉선은 마치산에서 나로우주발사대로 이어지는 계곡부에 대규모 군락을 이루어 분포하고 있다. 해변싸리, 백운산원추리, 좀비비추는 해안가 암벽 및 산 림 가장자리에서 출현하였다.

\section{식물구계학적 특정식물}

외나로도 일대의 식물구계학적 특정식물 중 $\mathrm{V}$ 등급은 대흥란, 석곡, 지네발란, 혹난초 4 분류군, IV등급은 꽃뀡 의다리, 맥도딸기, 자란, 거제물봉선 4 분류군, III등급은 무 엽란, 나도고사리삼, 불암초, 육박나무 등 47분류군, II등 급은 세뿔석위, 낙지다리, 약난초 등 18 분류군, I등급은 금족제비고사리, 긴화살여뀌, 무늬사초, 가는잎산들깨 등 64분류군으로 집계되었다(Table 5).

이는 국립생태원의 식물구계학적 특정식물 1,476 종 중 $9.28 \%$ 에 해당한다. 엷은지네고사리, 거제물봉선, 혹난초, 무엽란, 자란 등은 마치산 계곡에서 확인되었고, 이 지역

Table 4. The list of the endemic plants investigated in the Oenarodo Island.

\begin{tabular}{ll}
\hline \hline \multicolumn{1}{c}{ Family } & \multicolumn{1}{c}{ Scientific names/Korean names } \\
\hline Ranunculaceae 미나리아재비과 & Eranthis byunsanensis B. Y. Sun 변산바람꽃 \\
& Hepatica insularis Nakai 새끼노루귀 \\
& Thalictrum actaefolium var. brevistylum Nakai 은꿩의다리 \\
& Thalictrum uchiyamai Nakai 자주뀡의다리 \\
& Asarum maculatum Nakai 개족도리풀 \\
Aristolochiaceae 쥐방울덩굴과 & Lespedeza maritima Nakai 해변싸리 \\
Leguminosae 콩과 & Vicia hirticalycina Nakai 나래완두 \\
Balsaminaceae 봉선화과 & Impatiens koreana (Nakai) B. U. Oh 처진물봉선 \\
Oleaceae 물푸레나무과 & Forsythia koreana (Rehder) Nakai 개나리 \\
Rubiaceae 꼭두서니과 & Galium koreanum (Nakai) Nakai 참갈퀴덩굴 \\
Scrophulariaceae 현삼과 & Paulownia coreana Uyeki 오동나무 \\
Caprifoliaceae 인동과 & Weigela subsessilis (Nakai) L. H. Bailey 병꽃나무 \\
Liliaceae 백합과 & Hemerocallis hakuunensis Nakai 백 운원추리 \\
& Hosta minor (Baker) Nakai 좀비비추 \\
\hline
\end{tabular}

Table 5. The list of floristic regional indicator plants of Korea in Oenarodo Island by National Institute of Ecology (2018).

\begin{tabular}{llc}
\hline \hline \multicolumn{1}{c}{ Family } & \multicolumn{1}{c}{ Scientific names/Korean names } & Grade \\
\hline Orchidaceae 난초과 & Bulbophyllum inconspicuum Maxim. 혹난초 \\
& Cymbidium macrorrhizum Lindl. 대흥란 \\
& Dendrobium moniliforme (L.) Sw. 석곡 \\
& Sarcanthus scolopendrifolius Makino 지네 발란 & V \\
& Thalictrum petaloideum L. 꽃꿩의다리 \\
Ranunculaceae 미나리아재비과 & Rubus longisepalus Nakai 맥도딸기 \\
Rosaceae 장미과 & Bletilla striata (Thunb.) Rchb.f. 자란 \\
Orchidaceae 난초과 & Impatiens koreana (Nakai) B. U. Oh 처진물봉선 \\
Balsaminaceae 봉선화과 & Sceptridium japonicum (Prantl) Lyon. 산꽃고사리삼 \\
Ophioglossaceae 고사리삼과 &
\end{tabular}


Table 5. Continued.

\begin{tabular}{l}
\hline \hline Family name \\
\hline Gleicheniaceae 풀고사리과 \\
Dennstaedtiaceae 잔고사리과 \\
Aspleniaceae 꼬리고사리과 \\
Thelypteridaceae 처녀고사리과 \\
Dryopteridaceae 관중과 \\
Polypodiaceae 고란초과 \\
Lauraceae 녹나무과
\end{tabular}

Aristolochiaceae 쥐방울덩굴과 Schisandraceae 오미자과 Lardizabalaceae 으름덩굴과 Moraceae 뽕나무과 Urticaceae 쐐기풀과 Fagaceae 참나무과

Theaceae 차나무과 Sterculiaceae 벽오동과 Flacourtiaceae 이나무과 Ericaceae 진달래과 Pittosporaceae 돈나무과 Rosaceae 장미과

Elaeagnaceae 보리수나무과 Rhamnaceae 갈매나무과 Meliaceae 멀구슬나무과 Rutaceae 운향과 Araliaceae 두릅나무과

Umbelliferae 산형과

Verbenaceae 마편초과

Labiatae 꿀풀과

Oleaceae 물푸레나무과

Caprifoliaceae 인동과

Compositae 국화과

Cyperaceae 사초과

Gramineae 화본과

Liliaceae 백합과

Orchidaceae 난초과

Hymenophyllaceae 처녀이끼과 Polypodiaceae 고란초과

Ranunculaceae 미나리아재비과 Papaveraceae 양귀비과 Moraceae 뽕나무과 Betulaceae 자작나무과 Aizoaceae 번행초과

Scientific names/Korean names

Ophioglossum vulgatum L. 나도고사리삼

Dicranopteris pedata (Houtt.) Nakaike 발풀고사리

Gleichenia japonica Spreng. 풀고사리

Microlepia marginata (Panzer) C. Chr. 돌잔고사리

Asplenium sarelii Hk. 돌담고사리

Thelypteris acuminata (Houtt.) Morton 별고사리

Dryopteris pacifica (Nakai) Tagawa 큰족제비고사리

III

Lepisorus onoei (Franch. \& Sav.) Ching 애기일엽초

Actinodaphne lancifolia (Siebold \& Zucc.) Meisn. 육박나무

Cinnamomum japonicum Siebold ex Nees 생 달나무

Machilus japonica Siebold \& Zucc. 센달나무

Neolitsea aciculata (Blume) Koidz. 새덕이

Asarum maculatum Nakai 개족도리풀

Kadsura japonica (L.) Dunal 남오미자

Stauntonia hexaphylla (Thunb.) Decne. 멀꿀

Ficus erecta Thunb. 천선과나무

Boehmeria pannosa $\mathrm{Oka}$ 왕모시풀

Castanopsis sieboldii (Makino) Hatus. 구실잣밤나무

Quercus glauca Thunb. 종가시나무

Eurya emarginata (Thunb.) Makino 우묵사스레피

Melochia corchorifolia L. 불암초

Idesia polycarpa Maxim. 이나무

Vaccinium bracteatum Thunb. 모새나무

Pittosporum tobira (Thunb.) W. T. Aiton 돈나무

Raphiolepis indica var. umbellata (Thunb.) Ohashi 다정 큼나무

Rubus hirsutus Thunb. 장딸기

Elaeagnus glabra Thunb. 보리장나무

Sageretia theezans (L.) Brongn. 상동나무

Melia azedarach L. 멀구슬나무

Poncirus trifoliata Raf. 탱자나무

Dendropanax morbiferum H. Lév. 황칠나무

Fatsia japonica (Thunb.) Decne. \& Planch. 팔손이

Sanicula tuberculata Maxim. 애기참반디

Callicarpa mollis Siebold \& Zucc. 새비나무

Verbena officinalis L. 마편초

Salvia japonica Thunb. 둥근배암차즈기

Chionanthus retusus Lindl. \& Paxton 이팝나무

Viburnum odoratissimum var. awabuki (K. Koch) Zabel ex Rumpler 아왜나무

Farfugium japonicum (L.) Kitam. 털머위

Carex ligulata Nees 갈사초

Lophatherum gracile Brongn. 조릿대풀

Asparagus cochinchinensis (Lour.) Merr. 천문동

Ophiopogon jaburan (Kunth) Lodd. 맥문아재비

Polygonatum falcatum A. Gray 진황정

Cremastra variabilis (Blume) Nakai 약난초

Lecanorchis japonica Blume 무엽란

Crepidomanes minutum (Blume) K. Iwats. 부채괴불이끼

II

Crypsinus hastatus (Thunb.) Copel. 고란초

Pyrrosia hastata (Thunb. ex Houtt.) Ching 세뿔석위

Ranunculus silerifolius H. Lév. 왜젓가락풀

Hylomecon vernalis Maxim. 피나물

Ficus oxyphylla Miq. ex Zoll. 모람

Alnus japonica (Thunb.) Steud. 오리나무

Tetragonia tetragonoides (Pall.) Kuntze 번행초 
Table 5. Continued.

\begin{tabular}{|c|c|c|}
\hline Family name & Scientific names/Korean names & Grade \\
\hline$\overline{\text { Caryophyllaceae 석죽과 }}$ & Silene aprica var. oldhamiana (Miq.) C. Y. Wu 갯장구채 & \\
\hline Crassulaceae 돌나물과 & Penthorum chinense Pursh 낙지다리 & \\
\hline Saxifragaceae 범의귀과 & Chrysosplenium pilosum var. valdepilosum Ohwi 금갱이눈 & \\
\hline Rosaceae 장미과 & Potentilla yokusaiana Makino 민눈양지꽃 & \\
\hline Umbelliferae 산형과 & Angelica tenuissima Nakai 고본 & \\
\hline Convolvulaceae 메꽃과 & Calystegia soldanella (L.) Roem. \& Schultb. 갯메꽃 & \\
\hline Verbenaceae 마편초과 & Vitex rotundifolia L.f. 순비기나무 & \\
\hline Scrophulariaceae 현삼과 & Scrophularia kakudensis Franch. 큰개현삼 & \\
\hline Alismataceae 택사과 & Alisma canaliculatum A. Braun \& C. D. Bouché 택사 & \\
\hline Orchidaceae 난초과 & Epipactis thunbergii A.Gray 닭의난초 & \\
\hline Schizaeaceae 실고사리과 & Lygodium japonicum (Thunb.) Sw. 실고사리 & I \\
\hline Pteridaceae 봉의꼬리과 & Pteris multifida Poir. 봉의꼬리 & \\
\hline \multirow[t]{3}{*}{ Dryopteridaceae 면마과 } & Dryopteris erythrosora (D. C. Eaton) Kuntze 홍지네고사리 & \\
\hline & Dryopteris gymnophylla (Bak.) C. Chr. 금족제비고사리 & \\
\hline & Polystichum polyblepharum (Kunze) C. Presl 나도히초미 & \\
\hline \multirow[t]{2}{*}{ Polypodiaceae 고란초과 } & Lemmaphyllum microphyllum C. Presl 콩짜개 덩굴 & \\
\hline & Lepisorus thunbergianus (Kaulf.) Ching 일엽초 & \\
\hline \multirow[t]{4}{*}{ Lauraceae 녹나무과 } & Lindera erythrocarpa Makino 비목나무 & \\
\hline & Lindera glauca (Siebold \& Zucc.) Blume 감태나무 & \\
\hline & Machilus thunbergii Siebold \& Zucc. 후박나무 & \\
\hline & Neolitsea sericea (Blume) Koidz. 참식나무 & \\
\hline Chloranthaceae 홀아비꽃대과 & Chloranthus fortunei (A. Gray) Solms 옥녀꽃대 & \\
\hline \multirow[t]{3}{*}{ Ranunculaceae 미나리아재비과 } & Aconitum jaluense Kom. 투구꽃 & \\
\hline & Clematis patens $\mathrm{C}$. Morren \& Decne. 큰꽃으아리 & \\
\hline & Hepatica insularis Nakai 새끼노루귀 & \\
\hline \multirow[t]{2}{*}{ Sabiaceae 나도밤나무과 } & Meliosma myriantha Siebold \& Zucc. 나도밤나무 & \\
\hline & Meliosma oldhamii Maxim. 합다리나무 & \\
\hline \multirow[t]{3}{*}{ Ulmaceae 느릅나무과 } & Aphananthe aspera (Thunb.) Planch. 푸조나무 & \\
\hline & Celtis biondii Pamp. 폭나무 & \\
\hline & Carpinus turczaninowii Hance 소사나무 & \\
\hline Polygonaceae 마디풀과 & Polygonum breviochreatum Makino 긴화살여 뀌 & \\
\hline \multirow[t]{2}{*}{ Theaceae 차나무과 } & Camellia japonica L. 동백나무 & \\
\hline & Eurya japonica Thunb. 사스레피나무 & \\
\hline Cucurbitaceae 박과 & Gynostemma pentaphyllum (Thunb.) Makino 돌외 & \\
\hline Salicaceae 버드나무과 & Salix chaenomeloides Kimura 왕버들 & \\
\hline Ericaceae 진달래과 & Vaccinium oldhamii Miq. 정금나무 & \\
\hline Symplocaceae 노린재나무과 & Symplocos tanakana Nakai 검노린재 & \\
\hline Myrsinaceae 자금우과 & Ardisia japonica (Thunb.) Blume 자금우 & \\
\hline Primulaceae 앵초과 & Lysimachia mauritiana Lam. 갯까치수염 & \\
\hline Hydrangeaceae 수국과 & Deutzia parviflora Bunge 말발도리 & \\
\hline \multirow[t]{3}{*}{ Rosaceae 장미과 } & Pourthiaea villosa (Thunb.) Decne. 윤노리나무 & \\
\hline & Rosa wichuraiana Crép. 돌가시나무 & \\
\hline & Spiraea blumei G. Don 산조팝나무 & \\
\hline \multirow[t]{2}{*}{ Leguminosae 콩과 } & Lespedeza maritima Nakai 해변싸리 & \\
\hline & Vicia hirticalycina Nakai 나래완두 & \\
\hline Elaeagnaceae 보리수나무과 & Elaeagnus macrophylla Thunb. 보리밥나무 & \\
\hline \multirow[t]{3}{*}{ Celastraceae 노박덩굴과 } & Celastrus stephanotiifolius Makino 털노박덩굴 & \\
\hline & Euonymus fortunei (Turcz.) Hand.-Mazz. 좀사철나무 & \\
\hline & Euonymus japonicus Thunb. 사철나무 & \\
\hline \multirow[t]{3}{*}{ Euphorbiaceae 대극과 } & Mallotus japonicus (Thunb.) Müell. Arg. 예덕나무 & \\
\hline & Neoshirakia japonica (Siebold \& Zucc.) Esser 사람주나무 & \\
\hline & Hovenia dulcis Thunb. 헛개나무 & \\
\hline Staphyleaceae 고추나무과 & Euscaphis japonica (Thunb.) Kanitz 말오줌때 & \\
\hline Rutaceae 운향과 & Orixa japonica Thunb. 상산 & \\
\hline
\end{tabular}


Table 5. Continued.

\begin{tabular}{|c|c|c|}
\hline Family name & Scientific names/Korean names & Grade \\
\hline \multirow[t]{2}{*}{ Ericaceae 진달래과 } & Vaccinium oldhamii Miq. 정금나무 & \\
\hline & Zanthoxylum planispinum Siebold \& Zucc. 개산초 & \\
\hline Araliaceae 두릅나무과 & Hedera rhombea (Miq.) Bean 송악 & \\
\hline Menyanthaceae 조름나물과 & Nymphoides peltata (Gmel.) Kuntze 노랑어리연꽃 & \\
\hline Verbenaceae 마편초과 & Caryopteris incana (Thunb.) Miq. 층꽃나무 & \\
\hline \multirow[t]{2}{*}{ Labiatae 꿀풀과 } & Ajuga decumbens Thunb. 금창초 & \\
\hline & Mosla chinensis Maxim. 가는잎산들깨 & \\
\hline Oleaceae 물푸레나무과 & Ligustrum japonicum Thunb. 광나무 & \\
\hline Rubiaceae 꼭두서니과 & Paederia scandens (Lour.) Merr. 계요등 & \\
\hline Compositae 국화과 & Lactuca scariola L. 개뽀리뱅이 & \\
\hline Araceae 천남성과 & Arisaema ringens (Thunb.) Schott 큰천남성 & \\
\hline \multirow[t]{5}{*}{ Cyperaceae 사초과 } & Carex dispalata A. Gray 삿갓사초 & \\
\hline & Carex doniana Spreng. 흰사초 & \\
\hline & Carex lenta D. Don 줄사초 & \\
\hline & Carex maculata Boott 무늬사초 & \\
\hline & Carex tristachya Thunb. 반들사초 & \\
\hline Gramineae 화본과 & Phacelurus latifolius (Steud.) Ohwi 모새달 & \\
\hline Gramineae 화본과 & Phaenosperma globosa Munro ex Benth. 산기장 & \\
\hline \multirow[t]{2}{*}{ Liliaceae 백합과 } & Hosta minor (Baker) Nakai 좀비비추 & \\
\hline & Ophiopogon japonicus (Thunb.) Ker Gawl. 소엽맥문동 & \\
\hline Orchidaceae난초과 & Cymbidium goeringii (Rchb. f.) Rchb. f. 보춘화 & \\
\hline
\end{tabular}

Table 6. The list of plants on the red list of Korea in Oenarodo Island by National Institute of Biological Resources.

\begin{tabular}{|c|c|c|}
\hline Family name & Scientific names/Korean name & Grade \\
\hline Ranunculaceae 미나리아재비과 & Thalictrum petaloideum L. 꽃꿩의다리 & CR \\
\hline Balsaminaceae 봉선화과 & Impatiens koreana (Nakai) B. U. Oh 거제물봉선 & $\mathrm{CR}$ \\
\hline \multirow[t]{2}{*}{ Orchidaceae 난초과 } & Dendrobium moniliforme (L.) Sw. 석곡 & $\mathrm{CR}$ \\
\hline & Sarcanthus scolopendrifolius Makino 지네 발란 & $\mathrm{CR}$ \\
\hline Ophioglossaceae 고사리삼과 & Ophioglossum vulgatum L. 나도고사리삼 & $\mathrm{EN}$ \\
\hline \multirow[t]{3}{*}{ Orchidaceae 난초과 } & Bulbophyllum inconspicuum Maxim. 혹난초 & EN \\
\hline & Cymbidium macrorrhizum Lindl. 대흥란 & EN \\
\hline & Lecanorchis japonica Blume 무엽란 & EN \\
\hline Polypodiaceae 고란초과 & Pyrrosia hastata (Thunb. ex Houtt.) Ching 세뿔석 위 & VU \\
\hline Umbelliferae 산형과 & Bupleurum falcatum L. 시호 & $\mathrm{VU}$ \\
\hline Labiatae 꿀풀과 & Mosla japonica (Benth.) Maxim. 산들깨 & VU \\
\hline \multirow[t]{2}{*}{ Orchidaceae 난초과 } & Bletilla striata (Thunb.) Rchb. f. 자란 & VU \\
\hline & Cremastra variabilis (Blume) Nakai 약난초 & $\mathrm{VU}$ \\
\hline Chloranthaceae 홀아비꽃대과 & Chloranthus fortunei (A. Gray) Solms 옥녀꽃대 & DD \\
\hline Labiatae 꿀풀과 & Mosla chinensis Maxim. 가는잎산들깨 & DD \\
\hline Cyperaceae 사초과 & Carex ligulata Nees 갈사초 & DD \\
\hline
\end{tabular}

CR, critically endangered; EN, endangered; VU, vulnerable; DD, data deficient.

은 나로우주센터와 인접하고 있어 사람들의 출입이 제한 되어 있는 것으로 확인되었다. 낙지다리는 편백나무숲에 서 봉래산 주차장으로 가는 길가 습지와 저지대의 묵논 습지에서 확인되었다.

\section{희귀식물}

조사지역 일대의 희귀식물은 10 과 16 분류군이 조사되 었고(Table 6), IUCN 평가기준에 따라 지정한 "한국희귀식 물목록집”(Korea National Arboretum, 2008)에서 희귀식물
571 분류군의 $2.8 \%$ 에 해당한다. 위급종등급(critically endangered, $\mathrm{CR})$ 의 꽃낑의다리, 거제물봉선, 석곡, 지네발 란, 위기종(endangered, EN)의 나도고사리삼, 혹난초, 대흥 란, 무엽란, 취약종(vulnerable, VU)의 세뿔석위, 시호, 산들 깨, 자란, 약난초, 정보부족종(data deficient, DD)의 옥녀꽃 대, 가는잎산들깨, 갈사초의 총 16 분류군이 확인되었다.

\section{귀화식물}

외나로도 일대의 귀화식물은 13 과 46 분류군의 생육이 
Table 7. The list of naturalized plants to Korea in Oenarodo Island.

\begin{tabular}{|c|c|c|}
\hline Family name & Scientific names/Korean name & Grade \\
\hline \multirow[t]{2}{*}{ Polygonaceae 마디풀과 } & Rumex crispus L. 소리쟁이 & \\
\hline & Rumex obtusifolius L. 돌소리쟁이 & \\
\hline Phytolaccaceae 자리공과 & Phytolacca americana L. 미국자리공 & \\
\hline \multirow[t]{2}{*}{ Caryophyllaceae 석죽과 } & Cerastium glomeratum Thuill. 유럽 점나도나물 & \\
\hline & Silene armeria L. 끈끈이대나물 & \\
\hline Chenopodiaceae 명아주과 & Chenopodium ambrosioides L. 양명아주 & \\
\hline Amaranthaceae 비름과 & Amaranthus viridis L. 청비름 & \\
\hline Saururaceae 삼백초과 & Houttuynia cordata Thunb. 약모밀 & \\
\hline \multirow[t]{3}{*}{ Cruciferae 십자화과 } & Brassica juncea (L.) Czern. 갓 & \\
\hline & Lepidium virginicum L. 콩다닥냉이 & \\
\hline & Thlaspi arvense L. 말냉이 & \\
\hline \multirow[t]{6}{*}{ Leguminosae 콩과 } & Lotus corniculatus L. 서양벌노랑이 & \\
\hline & Medicago sativa L. 자주개자리 & \\
\hline & Melilotus alba Medicus 흰전동싸리 & \\
\hline & Melilotus suaveolens Ledeb. 전동싸리 & \\
\hline & Trifolium pratense L. 붉은토끼풀 & \\
\hline & Trifolium repens L. 토끼풀 & \\
\hline Euphorbiaceae 대극과 & Euphorbia supina Raf. 애기땅빈대 & \\
\hline Solanaceae 가지과 & Physalis angulata L. 땅꽈리 & \\
\hline \multirow[t]{2}{*}{ Scrophulariaceae 현삼과 } & Veronica arvensis L. 선개불알풀 & \\
\hline & Veronica persica Poir. 큰개불알풀 & \\
\hline \multirow[t]{7}{*}{ Compositae 국화과 } & Aster subulatus Michx. 비짜루국화 & \\
\hline & Aster subulatus var. sandwicensis A. G. Jones 큰비짜루국화 & \\
\hline & Bidens frondosa L. 미국가막사리 & \\
\hline & Chrysanthemum leucanthemum L. 불란서국화 & \\
\hline & Conyza canadensis (L.) Cronquist 망초 & \\
\hline & Coreopsis lanceolata L. 큰금계국 & \\
\hline & Cosmos bipinnatus Cav. 코스모스 & \\
\hline \multirow[t]{9}{*}{ Compositae 국화과 } & Crassocephalum crepidioides (Benth.) S. Moore 주홍서나물 & \\
\hline & Erigeron annuus (L.) Pers. 개망초 & \\
\hline & Helianthus tuberosus L. 뚱딴지 & \\
\hline & Lactuca scariola L. 가시상추 & 교란 \\
\hline & Senecio vulgaris $\mathrm{L}$. 개쑥갓 & \\
\hline & Sonchus asper (L.) Hill 큰방가지똥 & \\
\hline & Sonchus oleraceus L. 방가지똥 & \\
\hline & Tagetes minuta L. 만수국아재비 & \\
\hline & Xanthium strumarium L. 도꼬마리 & \\
\hline \multirow[t]{9}{*}{ Gramineae 화본과 } & Avena fatua L. 메귀리 & \\
\hline & Bromus secalinus L. 큰참새귀리 & \\
\hline & Bromus unioloides H. B. K. 큰이삭풀 & \\
\hline & Dactylis glomerata L. 오리새 & \\
\hline & Eragrostis curvula Nees 능수참새그령 & \\
\hline & Festuca arundinacea Schreb. 큰김의털 & \\
\hline & Lolium multiflorum Lamarck 쥐보리 & \\
\hline & Lolium perenne L. 호밀풀 & \\
\hline & Paspalum distichum L. 물참새피 & 교란 \\
\hline
\end{tabular}

확인되었으며(Table 7), 국화과가 $34.8 \%$ 로 가장 높은 비율 을 보였다. 현지에서 확인된 귀화식물은 대부분 종자번식 의 재생전략유형을 갖고 그 분포역을 확대하는 생육·생태 특성상 길 가장자리, 숲 가장자리, 그리고 묵논 등에 주로 분포하였다. 한편, 생육이 확인된 귀화식물 중 환경부지
정 생태계교란야생식물은 가시상추, 물참새피 총 2 분류 군이 확인되었다(Table 7). 본 조사지역의 귀화율(귀화식 물의 종류수/출현식물의 전 종류수× 100$)$ 은 $7.83 \%$ 이고, 도 시화지수(UI: 본 지역의 귀화식물 종수/남한의 귀화식물 총 종수 $\times 100)$ 는 $14.33 \%$ 로 나타났다. 


\section{고 찰}

본 연구는 전라남도 고흥군에 위치하는 외나로도를 대 상으로 2015년 3월부터 2017년 10월까지 3년에 걸쳐 122 과 587분류군이 조사되었다. 외나로도에서 수행된 식물 상 연구는 Hwang et al. (2014)에 의하여 117과 574분류군이 보고되었다. Hwang et al. (2014)의 선행연구와 종합하여 집 계된 외나로도의 관속식물은 131 과 797 분류군이다. 이중 에서 본 연구에서 재확인된 분류군은 369 분류군이며, 218 분류군은 새롭게 조사되었다(Appendix 1). 한편, Hwang et al. (2014)의 식물상 연구에서 언급된 산외(Schizopepon bryoniifolius Maxim), 난장이바위솔(Meterostachys sikokianus (Makino) Nakai), 산벚나무(Prunus sargentii Rehder), 산돌배 나무(Pyrus ussuriensis Maxim.) 등은 남부이북에 분포하는 종으로 분포 기록이 의심스러운 분류군이 포함되어 재확 인을 필요로 한다.

본 연구에서 확인된 멸종위기야생생물은 $\Pi$ 급인 혹난 초는 마치산에서 나로발사대로 향하는 계곡에 군락을 이 루어 바위겉에 자생하는 것을 확인하였다. 본 지역은 우 주발사대 서측 계곡에 민간인 출입금지 구역으로 인위적 인 훼손은 없을 것이다. 지네발란은 장포산 남사면 암석 지 바위표면에 대군락을 이루어 분포하고 있었고, 신금리 해안도로 절개지와 나로2대교 남측 사면 암석지에서도 확인되었다. 지네발란은 산발적으로 광범위하게 분포하 고 있는 것이 확인되었다. 석곡은 나로우주발사대 동측 바위겉에 3 개체가 분포하고 있고, 장포산 남사면 절벽에 2개 집단이 생육하는 것을 확인하였다. 나로우주발사대 는 민간이 출입금지구역이며, 장포산의 자생지는 절벽에 위치하여 사람의 손길이 닿지 않는 곳에 위치한다. 따라 서 인위적인 훼손은 없을 것이다. 반면, 대흥란은 봉래산 에서 장포산으로 이어지는 계곡 사면에 2 개의 소수집단 이 분포하고 있다. 대흥란은 동백나무숲 등산로에 위치하 고 있어 탐방객으로 인한 훼손이 우려되어 철저한 자생지 보존 대책을 수립해야 한다. 정보부족종(DD)의 옥녀꽃대, 갈사초는 장포산 서측 사면부에서 확인되었고, 가는잎산 들깨는 봉래면 신금리 산림의 노출된 암석위에서 확인되 었다. 외나로도 일대에서 조사된 대부분의 희귀식물은 민 간인 출입이 통제된 마치산 동측의 계곡부 및 산림에서 발견되었다. 나로우주센터의 건립으로 인해 이 지역에는 허가되지 않은 민간인의 출입이 제한되어 다양한 희귀식 물이 자생하는 것으로 생각된다.

본 조사를 통하여 외나로도에는 다양한 한반도 고유 관 속식물이 분포하고 있으며 멸종위기종으로 지정된 혹난 초, 지네발란, 대흥란 및 석곡의 4종이 분포하고 있는 것이 확인되었다. 이 중 혹난초와 지네발란은 비교적 큰 규모 로 군락을 이루고 있음이 밝혀졌다. 이들 난과의 4종은 모 두 바위 또는 고목에 부착하여 서식하는 착생란들로서 우 리나라에서는 남부 해안 지역 및 제주도에 매우 재한적으
로 분포하고 있다. 외나로도가 다도해해상국립공원에 포 함되어 있어서 조사 지역 전체가 보호되고 있지만, 외나 로도에는 나로우주센터로 인해 민간이 출입이 통제되는 지역을 포함하고 있어서 이 지역의 식물상은 다른 지역에 비해 인간의 간섭이 매우 적다고 볼 수 있다.

본 연구는 국립공원 및 생태계 보호 지역 등 생물다양성 보존을 위해 직접적으로 설정된 보호지역 외에 나로우주 센터를 중심으로 한 다른 목적으로 민간인의 왕래가 통제 된 지역이 생물다양성 보존에 매우 중요하다는 점을 암시 한다. 이 지역에 분포하는 멸종위기종 및 한반도 고유종 은 주변지역으로 전파될 수 있는 기원지(source area) 역할 을 할 것으로 여겨진다. 최근 특수목적으로 인간의 출입 이 통제된 군사시설 내의 지역 또는 과거에 군사시설로 사용되어 오다가 냉전 이후에 폐쇄된 지역이 생물다양성 보존에 매우 중요하다는 연구 결과들이 제시되고 있다 (Zentelis and Lindenmayer, 2014; Ellwanger and Rieter, 2019). 본 연구에서 밝혀진 결과는 향후 지속적인 모니터링을 통 해 민간인의 출입이 전면 통제된 이후에 식물상이 어떻게 보존되는지 파악할 수 있는 기초 자료를 제공할 것이다.

ORCID: Seung Hyun HWANG https://orcid.org/0000-00029076-9379; Eun Hwa LA https://orcid.org/0000-0003-14712626; Jin Woong LEE https://orcid.org/0000-0001-9796-7944; Jin Kap AHN https://orcid.org/0000-0002-3843-028X

\section{Acknowledgments}

This work was supported by a grant (NIBR201701202) from the National Institute of Biological Resources (NIBR) funded by the Ministry of Environment (MOE), Republic of Korea.

\section{Conflict of Interest}

The authirs declare that there are no conflicts of interest.

\section{Literature Cited}

Ellwanger, G. and K. Rieter. 2019. Nature conservation on decommissioned military training areas: German approaches and experiences. Journal for Nature Conservation 49: 1-8.

Hwang, H.-S., S. Y. Jung, J. W. Jang, J. C. Yang, K. S. Chang and S. H. Oh. 2014. Distribution characteristics of vascular plants in Oenarodo Island (Goheung, Jeollanam-do). Korean Journal of Plant Resources 27:485-500.

Kim, H. H., D. B. Kim, H. K. Won, C. S. Kim and W. S. Kong. 2016. Island-biogeographical characteristics of insular flora in southern sea of Jeollanamdo, Korea. Journal of Climate Change Research 7: 143-155. 
Kim H.-S. and J.-G. Oh. 2010. Distribution of naturalized plants in Dadohae National Marine Park. Korean Journal of Plant Resources 23: 187-196.

Kim J. G. and M. S. Park. 2004 Ecological Survey of the Natural Environment Goheung: Plants. Institute of Basic Science, Sunchon National University, Goheung, 189 pp.

Kim, Y.-S. and K.-K. Oh. 1997. Restoration model of evergreen broad-leaved forests in warm temperate region (III). Korean Journal of Environment and Ecology 11: 61-83. (in Korean)

Korea National Arboretum and The Korean Society of Plant Taxonomists. 2007. A Synonymic List of Vascular Plant in Korea. Korea National Arboretum, Pocheon, 534 pp (in Korean).

Korea National Arboretum 2008. Rare Plants Data Book in Korea. Korea National Arboretum, Pocheon, 332 pp. (in Korean)

Lee, T. B. 1980. Illustrated Flora of Korea. Hyangmunsa, Seoul, 990 pp. (in Korean)

Lee, T. B. 2003. Coloured Flora of Korea. Hyangmunsa, Seoul, Vol. 1, 914 pp, Vol. 2, 910 pp. (in Korean)

Lee, W.-C. and Y.-J. Yim. 2002. Plant Geography. Kangwon National University Press, Chuncheon, 412 pp. (in Korean)

Lee, W. T. 1996. Standard Illustrations of Korean Plants. Academy Press, Seoul, 624 pp. (in Korean)

Lee, Y.-M., S.-H. Park, S.-Y. Jung, S.-H. Oh and J.-C. Yang. 2011. Study on the current status of naturalized plants in South Korea. Korean Journal Pant Taxonomy 41: 87-101. (in
Korean)

Lee, Y. N. 1998. Flora of Korea. Kyohaksa Publishing Co., Seoul, 1237 pp. (in Korean)

Lee, Y. N. 2006. New Flora of Korea, Vol. I, II. Kyokaksa Publishing Co., Seoul, Vol. 1,

975 pp, Vol. 2, 885 pp. (in Korean)

National Institute of Biological Resources. 2019. National Species List of Korea: Vascular Plants. National Institute of Biological Resources, Incheon Vol. 1: 51-206. (in Korean)

National Institute of Biological Resources. 2012. Red Data Book of Endangered Vascular Plants in Korea. Econature, Seoul. 390 Pp. (in Korean).

National Institute of Biological Resources. 2014. Endemic Species of Korea: Plantae. National Institute of Biological Resources, Incheon. 912 Pp(in Korean)

National Institute of Ecology. 2018. Floristic Taget Specie (FT species) in Korea. National Institute of Ecology, $728 \mathrm{Pp}$. (in Korean)

Park, M. S. 2007. Vegetation of Narodo Islet. The Journal of Korean Institute of Forest Recreation 11: 25-34. (in Korean)

Park, S. H. 2009. New Illustrations and Photographs of Naturalized Plant of Korea. Ilchokak Publishing, Seoul, 575 pp. (in Korean)

Zentelis, R. and D. Lindenmayer. 2014. Manage military land for the environment. Nature 516: 170 .

\section{외나로도의 관속식물상}

황승현 · 라은화 ${ }^{1} \cdot$ 이진웅 ${ }^{2} \cdot$ 안진갑 $^{1 *}$

대전대학교 생명과학과, ${ }^{1}$ 전북대학교 생명과학과, ${ }^{2}$ 자연환경복원연구원

적 요: 전라남도 고흥군에 위치하는 외나로도의 관속식물상을 조사하고 분포가 확인된 주요식물에 대해 논 의하였다. 2015년 3월부터 2017년 10월까지 3년 동안 총 21회의 현지조사에서 확보된 표본에 근거하여 관속 식물목록을 작성하였고, 국립생물자원관 표본관(KB)과 대전대 생물학과 표본실(TUT)에 수장하였다. 본 조사 에서 생육이 확인된 관속식물은 122과 364속 538종 6아종 41변종 2품종의 총 587분류군이다. 멸종위기야생 생물로는 혹난초, 지네발란, 대흥란, 석곡 4 분류군을 확인하였다. 한반도고유종은 변산바람꽃, 해변싸리, 거제물 봉선 등 14 분류군이었고, 식물구계학적 특정식물로는 V등급 4 분류군, IV등급 4분류군, III등급 47 분류군, II등급 18 분류군, I등급 64 분류군으로 총 137 분류군이 조사되었다. 적색식물목록종으로는 위급종(critically endangered) 꽃 뀡의다리를 포함하여 16 분류군을 확인하였다. 귀화식물로는 가시상추, 물참새피 등 46 분류군이 조사되었다.

주요어: 외나로도, 식물상, 한반도고유종, 멸종위기식물, 귀화식물 
Appendix 1. The list of vascular plants investigated in the Oenarodo Island.

\begin{tabular}{l}
\hline \hline Scientific Name/Korean Name/Voucher number \\
SELAGINELLACEAE Willk. 부처손과 \\
Selaginella tamariscina (P. Beauv.) Spring 부처손 OP004028, \\
KP346943
\end{tabular}

OPHIOGLOSSACEAE (R. Br.) C. Agardh 고사리삼과

Botrychium japonicum (Prantl) Underw. 산꽃고사리삼 OP004020, KP350748 t

Ophioglossum vulgatum L. 나도고사리삼 KP347095 ^ OSMUNDACEAE Martinov 고비과

Osmunda japonica Thunb. 고비 KP347086

HYMENOPHYLLACEAE Mart. 처녀이끼과

Crepidomanes minutum (Blume) K. Iwats. 부채괴불이끼 KP346944 GLEICHENIACEAE C. Presl 발풀고사리과

Dicranopteris linearis (Burm. f.) Underw. 발풀고사리 NP579947 ઔ Diplopterygium glaucum (Houtt.) Nakai 풀고사리 NP579945 LYGODIACEAE M. Roem. 실고사리과 Lygodium japonicum (Thunb.) Sw. 실고사리 KP350632 DENNSTAEDTIACEAE Lotsy 잔고사리과 Dennstaedtia hirsuta (Sw.) Miq. 잔고사리 OP003973 ᄎ

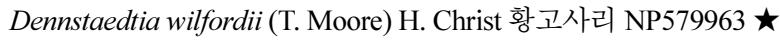
Microlepia marginata (Panz.) C. Chr. 돌잔고사리 KP350637 * PTERIDACEAE Rchb. 봉의꼬리과

Pteris multifida Poir. 봉의꼬리 NP580060, KP350653

ASPLENIACEAE Newman 꼬리고사리과

Asplenium incisum Thunb. 꼬리고사리 OP003981, KP350520, KP350611

Asplenium sarelii Hook. 돌담고사리 NP580071 ^

THELYPTERIDACEAE Pic. Serm. 처녀고사리과

Cyclosorus acuminatus (Houtt.) Nakai 별고사리 KP350608

Macrothelypteris oligophlebia var. elegans (Koidz.) Ching 각시고사 리 OP004059, KP350541

Phegopteris decursive-pinnata (H. C. Hall) Fée 설설고사리 OP004055, KP347094, KP350634

Thelypteris glanduligera (Kunze) Ching 사다리고사리 OP004012O, JP4079, KP350628

Thelypteris japonica (Baker) Ching 지네고사리 OP004054, KP350601

Thelypteris palustris (A. Gray) Schott 처녀고사리 KP350710

ATHYRIACEAE Alston 개고사리과

Athyrium niponicum (Mett.) Hance 개고사리

Athyrium yokoscense (Franch. \& Sav.) H. Christ 뱀고사리 OP003974

Deparia japonica (Thunb.) M. Kato 진고사리 OP004030, KP347098, KP350539, KP350746

\section{DRYOPTERIDACEAE Herter 관중과}

Cyrtomium falcatum (L. f.) C. Pres1 도깨비고비 OP004044, KP347062

Cyrtomium fortunei J. Sm. 쇠고비 OP004056

Dryopteris bissetiana (Baker) C. Chr. 산족제비고사리 OP003978, KP350675

Dryopteris chinensis (Baker) Koidz. 가는잎족제비고사리 OP004048, KP347029
Appendix 1. Continued.

Dryopteris erythrosora (D.C. Eaton) Kuntze 홍지네고사리 NP580045, KP350597

Dryopteris gymnophylla (Baker) C. Chr. 금족제비고사리 OP004004, KP347090

Dryopteris kinkiensis Tagawa 엷은지네고사리 OP003976 ^

Dryopteris lacera (Thunb.) Kuntze 비늘고사리 NP580035O, JP4003, KP347084, KP350538

Dryopteris pacifica (Nakai) Tagawa 큰족제비고사리 KP350630

Dryopteris sacrosancta Koidz. 애기족제비고사리 OP0040000, JP4007

Dryopteris saxifraga H. Itô 바위족제비고사리 KP350546, KP350627, KP350677

Dryopteris uniformis (Makino) Makino 곰비늘고사리 OP004005, KP347078, KP350540

Polystichum polyblepharum (Kunze) C. Presl 나도히초미

Polystichum tripteron (Kunze) C. Presl 십자고사리 KP347093

DAVALLIACEAE A. B. Frank 넉줄고사리과

Davallia mariesii Baker 넉줄고사리 OP003968, KP347027, KP350572, KP350606, KP350672

POLYPODIACEAE Bercht. \& J. Presl 고란초과

Crypsinus hastatus (Thunb.) Copel. 고란초 KP350534 ᄎ

Lemmaphyllum microphyllum C. Presl. 콩짜개덩굴 NP579968, KP346972

Lepisorus onoei (Franch. \& Sav.) Ching 애기일엽초 OP004027, KP350679

Lepisorus thunbergianus (Kaulf.) Ching 일엽초 NP580012

Pyrrosia hastata (Thunb.) Ching 세뿔석위 NP579988, KP346967

PINACEAE F. Rudolphi 소나무과

Pinus thunbergii Parl. 곰솔

CUPRESSACEAE Gray 측백나무과

Chamaecyparis obtusa (Siebold \& Zucc.) Endl. 편백 OP004033

Cryptomeria japonica (L. f.) D. Don 삼나무 OP004037, OP004146 Juniperus rigida Siebold \& Zucc. 노간주나무 OP004109

LAURACEAE Juss. 녹나무과

Actinodaphne lancifolia (Siebold \& Zucc.) Meisn. 육박나무 ^

Cinnamomum japonicum Siebold 생달나무

Lindera erythrocarpa Makino 비목나무 KP350524, KP350718

Lindera glauca (Siebold \& Zucc.) Blume 감태나무 OP003984, OP004105

Lindera obtusiloba Blume 생강나무 KP346990

Machilus japonica Siebold \& Zucc. 센달나무 OP004021

Machilus thunbergii Siebold \& Zucc. 후박나무 KP350593

Neolitsea aciculata (Blume) Koidz. 새덕이

Neolitsea sericea (Blume) Koidz. 참식나무 NP580004

CHLORANTHACEAE Sims 홀아비꽃대과

Chloranthus fortunei (A. Gray) Sloms 옥녀꽃대 NP580049, KP347074

SAURURACEAE T. Lestib. 삼백초과

Houttuynia cordata Thunb. 약모밀 KP350521

ARISTOLOCHIACEAE Juss. 쥐방울덩굴과

Asarum maculatum Nakai 개족도리풀 KP346992 
Appendix 1. Continued.

Asarum sieboldii Miq. 족도리풀 KP346993

SCHISANDRACEAE Blume 오미자과

Kadsura japonica (L.) Dunal 남오미자 OP004115

NELUMBONACEAE A. Rich. 연과

Nelumbo nucifera Gaertn. 연 $\star$

RANUNCULACEAE Juss. 미나리아재비과

Aconitum jaluense Kom. 투구꽃

Adonis pseudoamurensis W. T. Wang 개복수초

Anemone raddeana Regel 뀡의바람꽃 NP579970, KP346927, KP346989

Clematis apiifolia DC. 사위질빵 KP350656, KP350691

Clematis patens C. Morren \& Decne. 큰꽃으아리 NP580042, KP347038

Clematis terniflora DC. 참으아리 KP350696

Eranthis byunsanensis B.-Y. Sun 변산바람꽃 NP579967, KP346936 ᄎ Hepatica insularis Nakai 새끼노루귀 NP579972, KP346930

Pulsatilla cernua var. koreana (Nakai) U. C. L. 할미꽃 NP580032 ᄎ

Ranunculus cantoniensis DC. 털개구리미나리 NP580056, KP347067, KP350522

Ranunculus silerifolius H. Lév. 왜젓가락풀 OP004032

Thalictrum actaefolium var. brevistylum Nakai 은꿩의다리OP004015, KP350662

Thalictrum petaloideum L. 꽃꿩의다리 KP350659 ᄎ

Thalictrum uchiyamai Nakai 자주뀡의다리 NP579997 ^

MENISPERMACEAE Juss. 새모래덩굴과

Cocculus trilobus (Thunb.) DC. 댕댕이덩굴 OP003989, KP350640

LARDIZABALACEAE R. Br. 으름덩굴과

Akebia quinata (Thunb.) Decne. 으름덩굴

Stauntonia hexaphylla (Thunb.) Decne. 멀꿀 NP580065, KP350689

SABIACEAE Blume 나도밤나무과

Meliosma myriantha Siebold \& Zucc. 나도밤나무 KP350542

Meliosma oldhamii Maxim. 합다리나무

PAPAVERACEAE Juss. 양귀비과

Hylomecon vernalis Maxim. 피나물 NP579966, KP346963

FUMARIACEAE Marquis 현호색과

Corydalis heterocarpa Siebold \& Zucc. 염주괴불주머니 NP580027

Corydalis remota Maxim. 현호색 NP579973, KP346932, KP346986

Corydalis speciosa Maxim. 산괴불주머니 KP346981

EUCOMMIACEAE Engl. 두충과

Eucommia ulmoides Oliv. 두충 $\star$

ULMACEAE Mirb. 느릅나무과

Aphananthe aspera (Thunb.) Planch. 푸조나무 KP350636

Celtis biondii var. heterophylla (H. Lév.) C. K. Schneid. 폭나무 NP580001

Celtis jessoensis Koidz. 풍게나무 NP580009 *

Zelkova serrata (Thunb.) Makino 느티나무 NP580005, OP004034

CANNABACEAE Martinov 삼과

Humulus japonicus Siebold \& Zucc. 환삼덩굴 KP350719

MORACEAE Gaudich. 뽕나무과

Broussonetia kazinoki Siebold \& Zucc. 닥나무 KP350604 ^

Cudrania tricuspidata (Carriére) Lavallée 꾸지뽕나무 OP003987
Appendix 1. Continued.

Ficus erecta Thunb. 천선과나무 OP004011, KP347050

Ficus oxyphylla Zoll. 모람 NP580002, KP350619

URTICACEAE Juss. 쐐기풀과

Boehmeria longispica Steud. 왜모시풀 KP350745

Boehmeria nivea var. tenacissima (Gaudich.) Miq. 섬모시풀 OP004114

Boehmeria pannosa Oka 왕모시풀

Boehmeria platanifolia Franch. \& Sav. 개모시풀 OP004057

Boehmeria spicata (Thunb.) Thunb. 좀깨잎나무 KP350716

Pilea mongolica Wedd. 모시물통이

Pilea peploides (Gaudich.) Hook. \& Arn. 물통이 KP347076 ^

JUGLANDACEAE Perleb 가래나무과

Platycarya strobilacea Siebold \& Zucc. 굴피나무 OP004049

FAGACEAE Dumort. 참나무과

Castanea crenata Siebold \& Zucc. 밤나무 KP350530 ᄎ

Castanopsis sieboldii (Makino) T. Yamaz. \& Mashiba 구실잣밤나무 KP347044, KP350682

Quercus acutissima Carruth. 상수리나무 KP350651

Quercus glauca Thunb. 종가시나무 OP004019 ^

Quercus serrata Murray 졸참나무 OP003966

Quercus variabilis Blume 굴참나무 OP004035

BETULACEAE Gray 자작나무과

Alnus firma Siebold \& Zucc. 사방오리 NP579949

Alnus japonica (Thunb.) Steud. 오리나무

Carpinus turczaninowii Hance 소사나무 NP579986O, JP3967, KP347087

Corylus heterophylla Trautv. 난티잎개암나무 $\star$

Corylus sieboldiana Blume 참개암나무 Ł

PHYTOLACCACEAE R. Br. 자리공과

Phytolacca americana L. 미국자리공 KP350512, KP350514

AIZOACEAE Martinov 번행초과

Tetragonia tetragonoides (Pall.) Kuntze 번행초 KP350560

CHENOPODIACEAE Vent. 명아주과

Chenopodium ambrosioides L. 양명아주 OP004118

AMARANTHACEAE Juss. 비름과

Achyranthes japonica (Miq.) Nakai 쇠무릎 OP004053O, JFWVP0000004122, KP350763

Amaranthus deflexus L. 눈비름 OP004155

Amaranthus viridis L. 청비름

MOLLUGINACEAE Bartl. 석류풀과

Mollugo pentaphylla L. 석류풀

CARYOPHYLLACEAE Juss. 석죽과

Arenaria serpyllifolia L. 벼룩이자리 NP579960, NP580062

Cerastium glomeratum Thuill. 양점나도나물 NP579958, KP346997 ^

Cerastium holosteoides var. hallaisanense (Nakai) M. Mizush. 점나도

나물 NP580061, KP347013 ᄎ

Dianthus chinensis L. 패랭이꽃 KP350573

Pseudostellaria heterophylla (Miq.) Pax 개별꽃 KP346969

Pseudostellaria palibiniana (Takeda) Ohwi 큰개별꽃 KP346931, KP346975

Silene aprica Fisch. \& C.A. Mey 애기장구채 NP580013 ᄎ 
Appendix 1. Continued.

Silene aprica var. oldhamiana (Miq.) C. Y. $\mathrm{Wu}$ 갯장구채

Silene armeria L. 끈근이대나물 KP350594 ᄎ

Silene seoulensis Nakai 가는장구채 OP003998

Stellaria alsine var. undulata (Thunb.) Ohwi 벼룩나물 KP346958

Stellaria media (L.) Vill. 별꽃 NP579977

POLYGONACEAE Juss. 마디풀과

Fagopyrum esculentum Moench 메밀 OP004157, KP350578 *

Polygonum breviochreatum Makino 긴화살여뀌

Polygonum filiforme Thunb. 이삭여뀌 OP004024, KP350751

Polygonum japonicum Meisn. 흰꽃여뀌 KP350715

Polygonum lapathifolium L. 흰여뀌 OP004078, KP350732

Polygonum longisetum Bruijn 개여뀌 OP004067, KP350752

Polygonum sagittatum L. 미꾸리낚시 OP004136

Polygonum senticosum (Meisn.) Franch. \& Sav. 며느리밑씻개 KP350762

Polygonum thunbergii Siebold \& Zucc. 고마리 OP004154, KP350759 Rumex crispus L. 소리쟁이 KP350550

Rumex obtusifolius L. 돌소리쟁이

THEACEAE Mirb. 차나무과

Camellia japonica L. 동백나무 KP346984

Eurya emarginata (Thunb.) Makino 우묵사스레피나무 KP346939, KP350589

Eurya japonica Thunb. 사스레피나무 NP579961O, JFWVP0000004102, KP346940, KP350562

CLUSIACEAE Lindl. 물레나물과

Hypericum japonicum Thunb. 애기고추나물 KP350692 ^

Hypericum laxum (Blume) Koidz. 좀고추나물

TILIACEAE Juss. 피나무과

Corchoropsis tomentosa (Thunb.) Makino 수까치깨 $\star \mathrm{OP} 004061$, KP350685

STERCULIACEAE Vent. 벽오동과

Melochia corchorifolia L. 불암초 OP004124 ᄎ

FLACOURTIACEAE DC. 산유자나무과

Idesia polycarpa Maxim. 이나무

VIOLACEAE Batsch 제비꽃과

Viola acuminata Ledeb. 졸방제비꽃 NP580048, KP346998

Viola albida var. chaerophylloides (Regel) F. Maek. 남산제비꽃 NP579946, KP346977

Viola grypoceras A. Gray 낚시제비꽃 KP346979

Viola japonica Ging. 왜제비꽃 NP579951

Viola mandshurica W. Becker 제비꽃 KP346999

Viola phalmacrocarpa Maxim. 털제비꽃 KP346970 ᄎ

Viola rossii Hemsl. 고깔제비꽃 KP346985

Viola selkirkii Goldie 뫼제비꽃 KP346991 ᄎ

Viola yedoensis Makino 호제비꽃 KP346937

CUCURBITACEAE Juss. 박과

Gynostemma pentaphylla (Thunb.) Makino 돌외 OP004116, KP350753

SALICACEAE Mirb. 버드나무과

Salix chaenomeloides Kimura 왕버들

Salix koreensis Andersson 버드나무 KP346945 ᄎ
Appendix 1. Continued.

BRASSICACEAE Burnett 십자화과

Arabis hirsuta (L.) Scop. 털장대 KP347023 ᄎ

Brassica juncea (L.) Czern. 갓 NP579954, KP346942

Capsella bursa-pastoris (L.) Medik. 냉이 NP579959, KP346955

Cardamine fallax (O. E. Shculz) Nakai 좁쌀냉이 KP347002

Cardamine flexuosa With. 황새냉이 KP347083

Lepidium virginicum L. 콩다닥냉이 KP347088, KP350515

Rorippa indica (L.) Hiern 개갓냉이 NP580068

Thlaspi arvense L. 말냉이 NP579950

ERICACEAE Juss. 진달래과

Rhododendron mucronulatum Turcz. 진달래 NP579964

Rhododendron schlippenbachii Maxim. 철쭉 KP346974

Rhododendron yedoense for. poukhanense (H. Lév.) M. Sugim. 산철쭉

Vaccinium bracteatum Thunb. 모새나무 OP004158

Vaccinium oldhamii Miq. 정금나무 NP579990, KP350620

PYROLACEAE Lindl. 노루발과

Pyrola japonica Klenze ex Alef. 노루발 OP004039, KP350644

STYRACACEAE DC. \& Spreng. 때죽나무과

Styrax japonicus Siebold \& Zucc. 때죽나무 NP580010O,

JFWVP0000003970, KP347016, KP350641

Styrax obassia Siebold \& Zucc. 쪽동백나무 `

SYMPLOCACEAE Desf. 노린재나무과

Symplocos sawafutagi Nagam. 노린재나무 NP579981

Symplocos tanakana Nakai 검노린재 OP004089, KP347035

MYRSINACEAE R. Br. 자금우과

Ardisia japonica (Thunb.) Blume 자금우 OP003992

PRIMULACEAE Borkh. 앵초과

Androsace umbellata (Lour.) Merr. 봄맞이꽃 KP346957 ᄎ

Lysimachia clethroides Duby 큰까치수염 OP003965, KP350529, KP350616

Lysimachia japonica Thunb. 좀가지풀 NP580026, KP347019

Lysimachia mauritiana Lam. 갯까치수염 KP347065

PITTOSPORACEAE R. Br. 돈나무과

Pittosporum tobira (Thunb.) W. T. Aiton 돈나무 NP579976O, JP4041, KP347043, KP350553

HYDRANGEACEAE Dumort. 수국과

Deutzia parviflora Bunge 말발도리 NP580029

Philadelphus tenuifolius Maxim. 엷은잎고광나무 NP580011, KP347072

CRASSULACEAE J. St.-Hil. 돌나물과

Penthorum chinense Pursh 낙지다리 OP004119

Sedum bulbiferum Makino 말똥비름 KP347021, KP350525 ^

Sedum polytrichoides Hemsl. 바위채송화 OP003969, KP350612, KP350676

Sedum sarmentosum Bunge 돌나물 KP350526

SAXIFRAGACEAE Juss. 범의귀과

Chrysosplenium pilosum var. valdepilosum Ohwi 금괭이눈 NP579974, KP346933

ROSACEAE Juss. 장미과

Agrimonia pilosa Ledeb. 짚신나물 OP004023, OP004076, KP350754 
Appendix 1. Continued.

Aria alnifolia (Siebold \& Zucc.) Decne. 팥배나무 OP004085

Geum aleppicum Jacq. 큰뱀무

Geum japonicum Thunb. 뱀무 OP004052

Potentilla freyniana Bornm. 세 잎양지꽃 NP580007

Potentilla yokusaiana Makino 민눈양지 꽃 KP346968

Pourthiaea villosa (Thunb.) Decne. 윤노리나무 OP003991, KP347012

Prunus japonica var. nakaii (H. Lév.) Rehder 이스라지나무 NP580038, KP346973

Prunus persica (L.) Batsch 복숭아나무 NP579999, KP347055 Prunus verecunda (Koidz.) Koehne 개벚나무 KP346961, KP347077 ^ Pyrus pyrifolia (Burm. f) Nakai 돌배나무 KP346962

Raphiolepis indica var. umbellata (Thunb.) Ohashi 다정큼나무 NP580014, KP347081, KP350695

Rosa multiflora Thunb. 찔레나무 NP580020, KP347032

Rosa wichuraiana Crép. 돌가시나무 KP350548, KP350556 *

Rubus coreanus Miq. 복분자딸기 KP347033

Rubus crataegifolius Bunge 산딸기 KP347036 ᄎ

Rubus hirsutus Thunb. 장딸기 KP346954

Rubus oldhamii Miq. 줄딸기 KP347071

Rubus parvifolius L. 멍석 딸기 NP579982, KP347015

Rubus tozawai var. longisepalus (Nakai) J.Y.Yang 맥도딸기

Sanguisorba officinalis L. 오이풀 OP004073 ᄎ

Spiraea blumei G. Don 산조팝나무 KP347041 ᄎ

Spiraea prunifolia var. simpliciflora (Nakai) Nakai 조팝나무 KP346959 ᄎ

Stephanandra incisa (Thunb.) Zabel 국수나무 NP579984, KP347014 FABACEAE Lindl. 콩과

Albizzia julibrissin Durazz. 자귀나무 KP350701

Amphicarpaea bracteata ssp. edgeworthii (Benth.) H. Ohashi 새콩 KP350645

Caragana sinica (Buc'hoz) Rehder 골담초 $\star$

Chamaecrista nomame (Siebold) H. Ohashi 차풀 KP350735

Desmodium podocarpum DC. 개도둑놈의갈고리 KP350742 ᄎ

Desmodium podocarpum ssp. oxyphyllum (DC.) H. Ohashi 도둑놈의 갈고리 KP350643

Glycine soja Siebold \& Zucc. 돌콩 OP004150, KP350706

Indigofera kirilowii Palib. 땅비싸리 NP579992, KP347026

Indigofera amblyantha Craib 큰낭아초 KP350595, KP350703 ᄎ

Kummerowia striata (Thunb.) Schindl. 매듭풀 OP004060

Lespedeza bicolor Turcz. 싸리 KP350717

Lespedeza cyrtobotrya Miq. 참싸리 OP004088

Lespedeza maritima Nakai 해변싸리 KP350587, KP350684

Lespedeza maximowiczii C. K. Schneid. 조록싸리 OP003972O, JP3993, KP350527, KP350625

Lespedeza pilosa (Thunb.) Siebold \& Zucc. 괭이싸리 OP004127

Lespedeza tomentosa (Thunb.) Maxim. 개싸리 $\star$

Lespedeza virgata (Thunb.) DC. 좀싸리 OP004129, KP350647

Lotus corniculatus L. 서양벌노랑이

Medicago sativa L. 자주개자리 KP350574 ^

Melilotus albus Medik. 흰전동싸리 KP350569 ᄎ
Appendix 1. Continued.

Melilotus suaveolens Ledeb. 전동싸리 OP004113

Pueraria lobata (Willd.) Ohwi 칡 KP350700

Rhynchosia volubilis Lour. 여우콩

Sophora flavescens Aiton 고삼 KP350519

Trifolium pratense L. 붉은토끼풀 KP350596

Trifolium repens L. 토끼풀 KP347025

Vicia amoena Ser. 갈퀴나물 NP580069, KP346980 ᄎ

Vicia angustifolia L. 가는살갈퀴 NP579994, NP580023, KP346949, KP347005

Vicia hirsuta (L.) A. Gray 새완두 NP580022, KP346995

Vicia hirticalycina Nakai 나래완두 OP004008, KP347082 ^

Vicia tetrasperma (L.) Schreb. 얼치기완두 NP580046, KP347003 ^

Vicia unijuga A. Braun 나비나물 KP350738

Vigna angularis var. nipponensis (Ohwi) Ohwi \& H. Ohashi 새팥 KP350757

ELAEAGNACEAE Juss. 보리수나무과

Elaeagnus glabra Thunb. 보리장나무

Elaeagnus macrophylla Thunb. 보리밥나무 NP579955

Elaeagnus umbellata Thunb. 보리수나무 OP004017, OP004050

THYMELAEACEAE Juss. 팥꽃나무과

Edgeworthia chrysantha Lindl. 삼지닥나무 KP346929 ^

TRAPACEAE Dumort. 마름과

Trapa japonica Flerow 마름 OP004159

ONAGRACEAE Juss. 바늘꽃과

Circaea mollis Siebold \& Zucc. 털이슬 KP350760

Ludwigia epilobioides Maxim. 여뀌바늘 OP004111

ALANGIACEAE DC. 박쥐나무과

Alangium platanifolium var. trilobum (Miq.) Ohwi 박쥐나무 OP004058

CORNACEAE Bercht. \& J. Presl 층층나무과

Cornus kousa Miq. 산딸나무 OP003980, KP347057

Cornus macrophylla Wall. 곰의말채나무 OP004051, KP350516

SANTALACEAE R. Br. 단향과

Thesium chinense Turcz. 제비꿀 NP580040, KP347091, KP350646

CELASTRACEAE R. Br. 노박덩굴과

Celastrus orbiculatus Thunb. 노박덩굴 NP580055, KP347031, KP350642

Celastrus stephanotiifolius (Makino) Makino 털노박덩굴 NP579998

Euonymus alatus (Thunb.) Siebold 화살나무 NP580043, OP003971, KP347011, KP350558, KP350678

Euonymus fortunei (Turcz.) Hand.-Mazz. 좀사철나무 OP004046 Euonymus hamiltonianus Wall. 참빗살나무 OP004031, KP347030 ᄎ Euonymus japonicus Thunb. 사철나무 OP004010, KP350585

Euonymus oxyphyllus Miq. 참회나무 NP579980, KP350535, KP350624

EUPHORBIACEAE Juss. 대극과

Acalypha australis L. 깨풀 OP004066, KP350740

Euphorbia helioscopia L. 등대풀 NP579962, NP580057, KP346956 ^

Euphorbia supina Raf. 애기땅빈대

Mallotus japonicus (L. f.) Müll. Arg. 예덕나무 OP003995, KP350549 
Appendix 1. Continued.

$\overline{\text { Neoshirakia japonica (Siebold \& Zucc.) Esser 사람주나무 NP580008, }}$ OP004040, KP347080 ᄎ

Phyllanthus ussuriensis Rupr. \& Maxim. 여우주머니 OP004063, KP350720

RHAMNACEAE Juss. 갈매나무과

Hovenia dulcis Thunb. 헛개나무 NP580036

Rhamnus koraiensis C. K. Schneid. 털갈매나무 NP580006, OP004001

Sageretia thea (Osbeck) M. C. Johnst. 상동나무 NP579987, OP004137, KP347017

VITACEAE Juss. 포도과

Ampelopsis brevipedunculata (Maxim.) Trautv. 개머루 KP350586, KP350635

Parthenocissus tricuspidata (Siebold \& Zucc.) Planch. 담쟁이덩굴 KP350552

Vitis ficifolia var. sinuata (Regel) H. Hara 까마귀머루 OP004141, KP350648

Vitis flexuosa Thunb. 새머루 KP350531

POLYGALACEAE Hoffmanns. \& Link 원지과

Polygala japonica Houtt. 애기풀 NP580015

STAPHYLEACEAE Martinov 고추나무과

Euscaphis japonica (Thunb.) Kanitz 말오줌때 OP004106, KP347089, KP350570

Staphylea bumalda DC. 고추나무 KP350537, KP350600

ACERACEAE Juss. 단풍나무과

Acer pictum var. mono (Maxim.) Franch. 고로쇠나무 NP580003

ANACARDIACEAE R. Br. 옻나무과

Rhus javainca L. 붉나무 KP350690

SIMAROUBACEAE DC. 소태나무과

Picrasma quassioides (D. Don) Benn. 소태나무 OP004016, OP004029

MELIACEAE Juss. 멀구슬나무과

Melia azedarach L. 멀구슬나무 KP350650

RUTACEAE Juss. 운향과

Orixa japonica Thunb. 상산 KP347096

Poncirus trifoliatus (L.) Raf. 탱자나무

Zanthoxylum piperitum (L.) DC. 초피나무 KP347073

Zanthoxylum planispinum Siebold \& Zucc. 개산초 NP580054, KP350536

Zanthoxylum schinifolium Siebold \& Zucc. 산초나무 OP003964, KP350674

OXALIDACEAE R. Br. 괭이밥과

Oxalis corniculata L. 괭이밥 NP579983, KP347046, KP350588

Oxalis obtriangulata Maxim. 큰괭이밥 KP347092

GERANIACEAE Juss. 쥐손이풀과

Geranium nepalense Sweet 산이질풀 OP004149

Geranium thunbergii Lindl. \& Paxton 이질풀 KP350657, KP350765

BALSAMINACEAE A. Rich. 봉선화과

Impatiens koreana (Nakai) B. U. Oh Hemsl. 거제물봉선 OP004002 ARALIACEAE Juss. 두릅나무과

Aralia elata (Miq.) Seem. 두릅나무 OP004140

Dendropanax trifidus (Thunb.) H. Hara 황칠나무
Appendix 1. Continued.

Fatsia japonica (Thunb.) Decne. \& Planch. 팔손이

Hedera rhombea (Miq.) Bean 송악 NP579956, KP346935

APIACEAE Lindl. 미나리과

Angelica decursiva (Miq.) Franch. \& Sav. 바디나물 OP004139

Angelica tenuissima Nakai 고본 KP350671

Bupleurum falcatum L. 시호 KP350631

Cryptotaenia japonica Hassk. 파드득나물 OP004006, KP350756

Hydrocotyle ramiflora Maxim. 큰피막이 KP350517

Oenanthe javanica (Blume) DC. 미나리 KP350713

Osmorhiza aristata (Thunb.) Rydb. 긴사상자 KP347056, KP350532

Ostericum grosseserratum (Maxim.) Kitag. 신감채 OP004096

Peucedanum terebinthaceum (Trevir.) Turcz. 기름나물

Sanicula chinensis Bunge 참반디 OP004047, KP350755

Sanicula tuberculata Maxim. 애기참반디 OP004014, KP346971

Torilis japonica (Houtt.) DC. 사상자 OP004009

Torilis scabra (Thunb.) DC. 큰사상자 NP579985

GENTIANACEAE Juss. 용담과

Gentiana zollingeri Fawc. 큰구슬붕이 KP346988

APOCYNACEAE Juss. 협죽도과

Trachelospermum asiaticum (Siebold \& Zucc.) Nakai 마삭줄 OP003988, KP347018

ASCLEPIADACEAE Borkh. 박주가리과

Cynanchum wilfordii (Maxim.) Hook. f. 큰조롱 KP350582 ᄎ

SOLANACEAE Juss. 가지과

Lycium chinense Mill. 구기자나무 KP350638

Physalis alkekengi L. 꽈리 OP003983, KP347047 ^

Physalis angulata L. 땅꽈리

CONOVOLVULACEAE Juss. 메꽃과

Calystegia soldanella (L.) Roem. \& Schult. 갯메꽃 KP350555

MENYANTHACEAE Dumort. 조름나물과

Nymphoides peltata (S. G. Gmel.) Kuntze 노랑어리연 OP004151 BORAGINACEAE Juss. 지치과

Bothriospermum tenellum (Hornem.) Fisch. \& C. A. Mey. 꽃받이 KP347053

Trigonotis peduncularis (Trevis.) Baker \& S. Moore 꽃마리 NP580024

VERBENACEAE J. St.-Hil. 마편초과

Callicarpa japonica Thunb. 작살나무 KP350590

Callicarpa mollis Siebold \& Zucc. 새비나무 OP003994, KP350544, KP350622

Caryopteris incana (Houtt.) Miq. 층꽃나무 OP004101

Clerodendron trichotomum Thunb. 누리장나무 OP004036

Verbena officinalis L. 마편초 OP004156

Vitex rotundifolia L. f. 순비기나무

PHRYMACEAE Schauer 파리풀과

Phryma leptostachya var. oblongifolia (Koidz.) Honda 파리풀 OP003999

LAMIACEAE Martinov 꿀풀과

Ajuga decumbens Thunb. 금창초 KP346951

Clinopodium chinense var. parviflorum (Kudô) H. Hara 층층이꽃 OP004099, KP350743 
Appendix 1. Continued.

\begin{tabular}{|c|}
\hline Elsholtzia splendens $\mathrm{F}$. Maek. 꽃향유 $\star$ \\
\hline Isodon inflexus (Thunb.) Kudô 산박하 OP004081 $\star$ \\
\hline $\begin{array}{l}\text { Lamium album var. barbatum (Siebold \& Zucc.) Franch. \& Sav. 광대 } \\
\text { 수염 KP347052 }\end{array}$ \\
\hline Lamium amplexicaule L. 광대나물 KP346941 \\
\hline Leonurus japonicus Houtt. 익모초 KP350737 \\
\hline Mosla chinensis Maxim. 가는잎산들깨 $\star$ \\
\hline Mosla japonica (Oliv.) Maxim. 산들깨 OP004108 \\
\hline Mosla punctulata (J. F. Gmel.) Nakai 들깨풀 OP004072, KP350714 ^ \\
\hline Phlomis umbrosa Turcz. 속단 OP003985 \\
\hline Physostegia virginiana (L.) Benth. 꽃범의꼬리 $\star$ \\
\hline Prunella asiatica Nakai 꿀풀 KP350518 \\
\hline Salvia japonica Thunb. 둥근배암차즈기 OP004026, KP350621 \\
\hline Scutellaria indica L. 골무꽃 NP579989, KP347049, KP350571 ^ \\
\hline $\begin{array}{l}\text { Teucrium viscidum var. miquelianum (Maxim.) H. Hara 덩굴곽향 } \\
\text { OP004022 }\end{array}$ \\
\hline
\end{tabular}

PLANTAGINACEAE Juss. 질경이과

Plantago asiatica L. 질경이 KP347010

OLEACEAE Hoffmanns. \& Link 물푸레나무과

Chionanthus retusus Lindl. \& Paxton 이팝나무 NP580037 ^

Forsythia koreana (Rehder) Nakai 개나리 KP346946 ^

Fraxinus sieboldiana Blume 쇠물푸레 NP579978, KP347039

Ligustrum japonicum Thunb. 광나무 OP004018, OP004084, OP004144, KP350545, KP350686

Ligustrum obtusifolium Siebold \& Zucc. 쥐똥나무 OP003997 SCROPHULARIACEAE Juss. 현삼과

Lindernia micrantha D. Don 논뚝외풀 KP350705

Lindernia procumbens (Krock.) Borbás 밭뚝외풀 $\star$

Mazus pumilus (Burm. f.) Steenis 주름잎 KP350704

Melampyrum roseum Maxim. 꽃며느리밥풀 OP004091

Melampyrum roseum var. japonicum Franch. \& Sav. 수염며느리밥풀 KP350626 ᄎ

Paulownia coreana Uyeki 오동나무 ^

Phtheirospermum japonicum (Thunb.) Kanitz 나도송이풀 OP004080 Scrophularia kakudensis Franch. 큰개현삼 KP350744

Veronica arvensis L. 선개불알풀 NP580030, KP350599 ^

Veronica persica Poir. 큰개불알풀 NP579965, KP346982

Veronica polita ssp. lilacina (T. Yamaz.) T. Yamaz. 개불알풀 NP579957

ACNTHACEAE Juss. 쥐꼬리망초과

Justicia procumbens L. 쥐꼬리망초 OP004095, KP350729

CAMPANULACEAE Juss. 초롱꽃과

Codonopsis lanceolata (Siebold \& Zucc.) Trautv. 더덕 KP350666

RUBIACEAE Juss. 꼭두서니과

Galium gracilens (A. Gray) Makino 좀네 잎갈퀴 NP579996 ^

Galium koreanum (Nakai) Nakai 참갈퀴덩굴 KP347022

Galium spurium var. echinospermum (Wallr.) Hayek 갈퀴덩굴 NP580063

Paederia scandens (Lour.) Merr. 계요등 KP350639, KP350688

Rubia akane Nakai 꼭두서니 KP350750 ^

DIERVILLACEAE Pyck 병꽃나무과
Appendix 1. Continued.

Weigela subsessilis (Nakai) L.H. Bailey 병꽃나무 KP346994

CAPRIFOLIACEAE Juss. 인동과

Lonicera harae Makino 길마가지나무 KP346966

Lonicera japonica Thunb. 인동 KP347064, KP350554, KP350655

VIBURNACEAE Raf. 산분꽃나무과

Viburnum dilatatum Thunb. 가막살나무 KP350602

Viburnum erosum Thunb. 덜꿩나무 KP347045

Viburnum odoratissimum var. awabuki (K. Koch) Rümpler 아왜나무 KP350559

VALERIANACEAE Batsch 마타리과

Patrinia villosa (Thunb.) Juss. 뚝갈 KP350739

Valeriana fauriei Briq. 쥐오줌풀 NP580018 ᄎ

ASTERACEAE Bercht. \& J. Presl 국화과

Ainsliaea acerifolia Sch. Bip. 단풍취 KP350673

Artemisia japonica Thunb. 제비쑥 KP350734 ᄎ

Artemisia princeps Pamp. 쑥 OP004152, KP350722

Aster ageratoides Turcz. 까실쑥부쟁이

Aster ciliosus Kitamura 개쑥부쟁이 OP004110

Aster incisus Fisch. 가새쑥부쟁이 OP004120

Aster scaber Thunb. 참취 OP004133, KP350668

Aster subulatus Michx. 비짜루국화

Aster subulatus var. sandwicensis (H. Mann) A. G. Jones 큰비짜루국

화 OP004064

Aster yomena (Kitam.) Honda 쑥부쟁이

Atractylodes ovata (Thunb.) DC. 삽주 KP350610, KP350661

Bidens bipinnata L. 도깨비바늘 OP004069, KP350766

Bidens frondosa L. 미국가막사리

Breea segeta (Bunge) Kitam. 조뱅이 NP580067

Carpesium abrotanoides L. 담배풀 KP350764 `

Carpesium divaricatum Siebold \& Zucc. 긴담배풀 KP350747

Centipeda minima (L.) A. Braun \& Aschers. 중대가리풀 OP004070

Chrysanthemum leucanthemum L. 불란서국화 NP580064

Cirsium japonicum var. ussuriense (Regel) Kitam. 엉겅퀴 KP350633

Conyza canadensis (L.) Cronquist 망초 OP004065

Coreopsis lanceolata L. 큰금계국 KP350575

Cosmos bipinnatus Cav. 코스모스 OP004112 ᄎ

Crassocephalum crepidioides (Benth.) S. Moore 주홍서나물 KP350702

Crepidiastrum sonchifolium (Bunge) J. H. Pak \& Kawano 고들빼기 NP580034, KP347004

Dendranthema boreale (Makino) Kitam. 산국

Dendranthema zawadskii (Herbich) Tzvelev var. zawadskii 산구절초 $\star$

Eclipta prostrata (L.) L. 한련초 OP004068 ᄎ

Erigeron annuas (L.) Pers. 개망초 KP350581

Euchiton japonicus (Thunb.) Holub 풀솜나물 NP580041, OP004131, KP350563

Eupatorium japonicum Thunb. 등골나물 OP004100, KP350741

Eupatorium tripartitum (Makino) Murata \& H. Koyama 향등골나물 KP350728 *

Farfugium japonicum (L.) Kitam. 털머위

Helianthus tuberosus L. 뚱딴지 OP004142 ᄎ 
Appendix 1. Continued.

Hemistepta lyrata Bunge 지칭개 NP580021, KP347066

Ixeridium dentatum (Thunb.) Tzvelev 씀바귀 NP579991, NP580031,

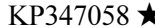

Lactuca scariola L. 가시상치

Lapsanastrum apogonoides (Maxim.) J. H. Pak \& K. Bremer 개보리 뺑이 KP347079

Petasites japonicus (Siebold \& Zucc.) Maxim. 머위 KP346983

Pseudognaphalium affine (D. Don) Anderb. 떡쑥 NP580053, KP347059

Senecio vulgaris L. 개쑥갓 NP579953, KP346953

Sigesbeckia glabrescens Makino 진득찰 KP350680 ᄎ

Sigesbeckia pubescens Makino 털진득찰 OP004098

Solidago virgaurea subsp. asiatica H. Hara 미역취 OP004132

Sonchus asper (L.) Hill. 큰방가지똥 OP004145

Sonchus brachyotus DC. 사데풀 OP004123

Sonchus oleraceus L. 방가지똥 KP346950, KP346996

Syneilesis palmata (Thunb.) Maxim. 우산나물 OP004013, KP350618

Tagetes minuta L. 만수국아재비 OP004148

Taraxacum mongolicum Hand.-Mazz. 털민들레 NP579952, KP346948

Tephroseris kirilowii (DC.) Holub 솜방망이 NP580033 ᄎ

Xanthium strumarium L. 도꼬마리 OP004147

ALISMATACEAE Vent. 택사과

Alisma canaliculatum A. Braun \& C.D. Bouché 택사 KP350733

ARACEAE Juss. 천남성과

Arisaema amurense Maxim 둥근잎천남성 KP346987

Arisaema ringens (Thunb.) Schott 큰천남성 KP347097

COMMELINACEAE Mirb. 닭의장풀과

Commelina communis L. 닭의장풀 OP003990, KP350614

Murdannia keisak (Hassk.) Hand.-Mazz. 사마귀풀OP004121

JUNCACEAE Juss. 골풀과

Juncus alatus Franch. \& Sav. 날개골풀 KP347060

Juncus effusus var. decipiens Buchenau 골풀 KP350579 ᄎ

Juncus papillosus Franch. \& Sav. 청비녀골풀 KP350725 ᄎ

Luzula capitata (Miq.) Kom. 뀡의밥 NP580050, KP347075 ᄎ

CYPERACEAE Juss. 사초과

Bulbostylis densa (Wall.) Hand.-Mazz. 꽃하늘지기

Carex aphanolepis Franch. \& Sav. 골사초

Carex benkei T. Shimizu. 긴화살사초

Carex bostrychostigma Maxim. 길뚝사초 KP347009

Carex ciliatomarginata Nakai 털대사초 KP346978

Carex dimorpholepis Steud. 이삭사초 KP347070

Carex dispalata A. Gray 삿갓사초 KP347051

Carex doniana Spreng. 흰사초 KP350605

Carex gibba Wahlenb. 나도별사초 NP580028, KP347020

Carex gifuensis Franch. 부산사초

Carex japonica Thunb. 개찌버리사초 KP350598

Carex lanceolata Boott 그늘사초 KP346926

Carex lenta D. Don 줄사초 NP579948O, JFWVP0000004083, KP350699
Appendix 1. Continued.

Carex ligulata var. austrokoreensis Ohwi 갈사초 NP580047, KP347069

Carex livida (Wahlenb.) Willd. 밀사초 KP346938 ^

Carex kamagariensis K. Okamoto. 큰청사초

Carex maculata Boott 무늬사초

Carex maximowiczii Miq. 왕비늘사초

Carex meridiana (Akiyama) Akiyama 갯바위청사초 KP347068

Carex polyschoena H. Lév. \& Vaniot 가지청사초 KP346947

Carex sabynensis Kunth 실청사초 KP346924

Carex sendaica Franch 홍노줄사초

Carex tristachya Thunb. 반들사초 NP580017 ^

Cyperus difformis L. 알방동산이 KP350724

Cyperus exaltatus var. iwasakii (Makino) T. Koyama 왕골 $\star$

Cyperus eragrostis Lam., Tabl. Encycl 열대방동산이

Cyperus globosus Forssk. 드렁방동산이 KP350687 ^

Cyperus hakonensis Franch. \& Sav. 병아리방동산이 KP350707

Cyperus iria $\mathrm{L}$. 참방동산이 $\mathrm{KP} 350727$

Cyperus microiria Steud. 금방동산이

Cyperus orthostachyus Franch. \& Sav. 쇠방동산이 KP350726 ^

Cyperus sanguinolentus Vahl 방동산이대가리

Eleocharis attenuata for. laeviseta (Nakai) Hara 참바늘골 KP350709 ^

Eleocharis mamillata var. cyclocarpa Kitag. 물꼬챙이골 KP350681

Fimbristylis autumnalis (L.) Roem. \& Schult. 애기하늘지기 KP350708

Fimbristylis dichotoma (L.) Vahl 하늘지기 KP350698

Fimbristylis hookeriana Boeck. 바위하늘지기

Fimbristylis miliacea (L.) Vahl 바람하늘지기 OP004117

Kyllinga brevifolia Rottb. 가시파대가리 KP350723

Lipocarpha microcephala (R. Br.) Kunth 세 대가리 KP350694 ^

Scirpus juncoides Roxb. 올챙이고랭이

Scirpus maritimus L. 매자기

Scirpus triqueter L. 세모고랭이 ᄎ

POACEAE Barnhart 화본과

Agropyron ciliare (Trin.) Franch. 속털개밀 KP350547, KP350566

Agropyron tsukushiense var. transiens (Hack.) Ohwi 개밀 NP580066, KP347054, KP350565

Agrostis alba L. 흰겨이삭 NP580039, KP347008

Arthraxon hispidus (Thunb.) Makino 조개풀 OP004093 ᄎ

Arundinella hirta (Thunb.) Tanaka 새OP004104, KP350615, KP350697

Avena fatua L. 메 귀리 NP580058

Beckmannia syzigachne (Steud.) Fernald 개피 KP350576

Brachypodium sylvaticum (Huds.) P. Beauv. 숲개밀

Bromus japonicus Thunb. 참새귀리 NP580052

Bromus pauciflorus Hack. 꼬리새

Bromus secalinus L. 큰참새귀리 KP350551

Bromus unioloides Kunth 큰이삭풀 KP346964, KP350577

Calamagrostis arundinacea (L.) Rroth 실새풀 OP004087

Capillipedium assimile (Steud.) A. Camus 나도기름새 OP004103

Cleistogenes hackelii (Honda) Honda 대새풀 OP004107 
Appendix 1. Continued.

Cymbopogon tortilis ssp. goeringii (Steud.) T. Koyama 개솔새 OP004074, KP350629

Dactylis glomerata L. 오리새 NP580051

Diarrhena fauriei (Hack.) Ohwi 광릉용수염풀 KP350664

Diarrhena mandshurica Maxim. 껍질용수염풀 OP003979

Digitaria violascens Link 민바랭이 OP004090, OP004130

Echinochloa crusgalli (L.) P. Beauv. 돌피 KP350721

Eleusine indica (L.) Gaertn. 왕바랭이 KP350730

Elymus dahuricus Griseb. 갯보리 KP350561

Eragrostis curvula (Schrad.) Nees 능수참새그령 KP350568 ^

Eragrostis ferruginea (Thunb.) P. Beauv. 그령 OP004153

Eragrostis multicaulis Steud. 비노리 ᄎ

Eragrostis pilosa (L.) P. Beauv. 큰비노리 ᄎ

Festuca arundinacea Schreb. 큰김의털NP580059, KP350567

Festuca myuros L. 들묵새 KP350513

Festuca parvigluma Steud. 김의털아재비 NP579993, KP347061

Imperata cylindrica var. koenigii (Retz.) Pilg. 띠 NP580016, KP347006

Koeleria cristata Pers. 도랑이피 NP580000

Lolium multiflorum Lam. 쥐보리 NP580025, KP350557

Lolium perenne L. 호밀풀 KP350580

Lophatherum gracile Brongn. 조릿대풀

Microstegium japonicum (Miq.) Koidz. 민바랭이새 OP004138

Microstegium vimineum (Trin.) A. Camus. 애기나도바랭이새

Microstegium vimineum var. polystachyum (Franch. \& Sav.) Ohwi 큰 듬성이삭새 $\mathrm{OP} 004134$

Miscanthus sacchariflorus (Maxim.) Hack. 물억새 $~$

Miscanthus sinensis Andersson 억새 OP004094, KP350761

Moliniopsis japonica (Hack.) Hayata 진퍼리새

Muhlenbergia japonica Steud. 쥐꼬리새 OP004097

Oplismenus undulatifolius (Ard.) Roem. \& Schult. 주름조개풀 KP350607, KP350665

Panicum bisulcatum Thunb. 개기장 KP350731

Paspalum distichum $\mathrm{L}$. 물참새피

Paspalum thunbergii Steud. 참새피 OP004128, KP350523, KP350652, KP350712

Pennisetum alopecuroides (L.) Spreng. 수크령 OP004135, KP350736 Phacelurus latifolius (Steud.) Ohwi 모새달

Phaenosperma globosa Benth. 산기장 OP004043, KP350591

Poa acroleuca Steud. 실포아풀 KP346960

Poa acroleuca var. submoniliformis Makino 마디포아풀 NP579979

Poa annua L. 새포아풀 KP346952

Poa sphondylodes Trin. 포아풀 KP347024

Sacciolepis indica (L.) Chase 좀물뚝새 OP004082, KP350693

Schizachyrium brebifolium (Sw.) Büse 쇠풀 OP004126 ᄎ

Setaria glauca (L.) P. Beauv. 금강아지풀 OP004062, KP350711

Setaria viridis (L.) P. Beauv. 강아지풀 KP350649, KP350749

Setaria viridis var. pachystachys (Franch. \& Sav.) Makino \& Nemoto 갯강아지풀 KP347063

Spodiopogon cotulifer (Thunb.) Hack. 기름새 OP004092

Sporobolus elongatus R. Br. 쥐꼬리새풀 OP004077, KP350758
Appendix 1. Continued.

Stipa pekinensis Hance 나래새 KP350663

Themeda triandra ssp. japonica (Willd.) T. Koyama 솔새 OP004075

Trisetum bifidum (Thunb.) Ohwi 잠자리피 NP580019, KP347007,

KP350564, KP350603

TYPHACEAE Juss. 부들과

Typha angustifolia L. 애기부들

ZINGIBERACEAE Martinov. 생강과

Zingiber mioga (Thunb.) Roscoe 양하 OP004038

PONTEDERIACECE Kunth 물옥잠과

Monochoria vaginalis var. plantaginea (Roxb.) Solms 물닭개비

LILIACEAE Juss. 백합과

Allium macrostemon Bunge 산달래 KP350592 ᄎ

Allium thunbergii G. Don 산부추 OP004071

Asparagus cochinchinensis (Lour.) Merr. 천문동 NP580070 ᄎ

Asparagus schoberioides Kunth 비짜루 KP347037, KP350583

Disporum smilacinum A. Gray 애기나리 KP347000

Gagea lutea (L.) Ker Gawl. 중의무릇 NP579971

Hemerocallis hakuunensis Nakai 백 운산원추리 KP350584

Hosta minor (Baker) Nakai 좀비비추 KP350613, KP350669 ^

Lilium tsingtauense Gilg 하늘말나리

Liriope platyphylla F. T. Wang \& T. Tang 맥문동 KP350658, KP350667

Liriope spicata (Thunb.) Lour. 개맥문동 OP003975

Ophiopogon jaburan (Siebold) Lodd. 맥문아재비

Ophiopogon japonicus (Thunb.) Ker Gawl. 소엽맥문동 OP004042 ᄎ

Polygonatum falcatum A. Gray 진황정 KP347048, KP350533

Polygonatum involucratum (Franch. \& Sav.) Maxim. 용둥굴레 NP579995, OP004025, KP347028, KP350609

Polygonatum lasianthum Maxim. 죽대 NP580044, OP003977, KP347042

Scilla scilloides (Lindl.) Druce 무릇 KP350623

Tulipa edulis (Miq.) Baker 산자고 NP579969, KP346976

IRIDACEAE Juss. 붓꽃과

Iris rossii Baker 각시붓꽃 KP346965

SMILACACEAE Vent. 청미래덩굴과

Smilax china L. 청미래덩굴 KP347001

Smilax nipponica Miq. 선밀나물 KP347040 ᄎ

Smilax riparia A. DC. 밀나물 OP003982, KP350543

Smilax sieboldii Miq. 청가시덩굴 KP347034

DIOSCOREACEAE R. Br. 마과

Dioscorea japonica Thunb. 참마 OP003986

Dioscorea quinqueloba Thunb. 단풍마 OP004143, KP350654, KP350683

Dioscorea tenuipes Franch \& Sav. 각시마 OP003996, OP004086, KP350617

ORCHIDACEAE Juss. 난초과

Amitostigma gracilis (Blume) Schltr. 병아리난초 KP350660 ^

Bletilla striata (Thunb.) Rchb. f. 자란

Bulbophyllum inconspicuum Maxim. 혹난초 KP350670 *

Cleisostoma scolopendrifolium (Makino) Garay 지네발란 $\star$

Cremastra appendiculata (D. Don) Makino 약난초 KP347085 ᄎ 
Appendix 1. Continued.

Cymbidium goeringii (Rchb. f.) Rchb. f. 보춘화 KP346934

Cymbidium macrorrhizon Lindl. 대흥란

Dendrobium moniliforme $\mathrm{Sw}$. 석곡

Epipactis thunbergii A. Gray 닭의난초 OP004045

Lecanorchis japonica Blume 무엽란 $\star$

Spiranthes sinensis (Pers.) Ames 타래난초 KP350528

OP, OJFWVP000000; KP, KOSPVP0000; NP, NIBRVP0000; JP,

JFWVP000000. $\star$ The asterisks indicate new to Oenarodo Island from Hwang et al. (2014). 